\title{
FREEZE-FRACTURE STUDIES ON BARLEY PLASTID MEMBRANES II. WILD-TYPE CHLOROPLAST
}

\author{
by \\ DAVID J. SIMPSON \\ Department of Physiology, Carlsberg Laboratory \\ Gamle Carlsberg Vej 10, DK-2500 Copenhagen, Valby
}

Keywords: Array, envelope, freeze-etch, spinach, thylakoids

\begin{abstract}
The ultrastructure of the thylakoids of barley chloroplasts was examined by freeze-fracturing and freeze-etching. Thylakoid fracture faces were objectively characterised in terms of the numbers of particles per square micron, average particle size and size distribution. Chloroplast envelope membranes were similarly examined and characterised. The changes in freeze-fracture appearance that occurred during greening are discussed in relation to current theories regarding thylakoid membrane structure. A procedure was developed that enables the induction of large numbers of particle arrays on the EF and PF faces and ES and PS surfaces of barley thylakoids. Measurements of the particles in these arrays revealed the asymmetric nature of EFs particles and confirmed that they span the thylakoid membrane.
\end{abstract}

\section{INTRODUCTION}

In a previous report (32) the freeze-fracture ultrastructure of the membranes of wild-type barley etioplasts was described and quantified. This paper is an extension of that study and examines the thylakoid and envelope membranes of barley chloroplasts. Although the freeze-fracture appearance of barley thylakoids is similar to that of spinach thylakoids $(22,36$, 37 , 38) there are quantitative differences. Values for the density and size distribution of freeze-fracture particles of barley thylakoids isolated from plants of specified age and grown under defined conditions of temperature and light are not available from existing studies on barley chloroplasts $(9,10,12,13,19,27,30)$. These values are needed, together with data obtained for barley etioplast membranes (32) as a basis for comparison with thylakoids from barley nuclear gene mutants affected in plastid development (33).

This paper describes the changes in the freeze-fracture ultrastructure of thylakoid and envelope membranes during the greening of etiolated barley seedlings. In addition, a simple procedure is reported that induces large numbers of particle arrays in the thylakoids of barley chloroplasts. These arrays are used to 
Figure 1. Low magnification micrograph of the freeze-fractured thylakoids from 7-day old wild-type barley seedlings. Four distinct faces can be recognised on the basis of the different sizes and densities of the particles. Note that the EFu and EFs faces are continuous with one another, as are the complementary PFu and PFs faces. $\times 117,000(\mathrm{Bar}=0.5 \mu \mathrm{m})$.

provide additional information about the shape of and relationship beween freeze-fracture particles.

\section{MATERIALS AND METHODS}

Seeds of wild-type barley (Hordeum vulgare cv. Svalöfs Bonus) were germinated in plastic trays containing vermiculite moistened with tap water. Seedlings were grown either for 6 days in darkness, followed by $24 \mathrm{~h}$ in white light (1700 lux provided by Sylvania F48T12-GRO-VHO Gro-lux fluorescent tubes) or for 7 days in continuous white light.

Chloroplasts were isolated from pre-cooled leaves by grinding in 2-3 volumes of ice-cold $0.6 \mathrm{M}$-glycerol, $0.1 \mathrm{M}$-tricine, $0.003 \mathrm{M}-\mathrm{Ca}\left(\mathrm{NO}_{3}\right)_{2}$ using a modified kitchen homogeniser (15). Destacking of the naked lamellar systems was achieved by washing once with $50 \mathrm{mM}$-tricine and twice with 5mM-tricine, pH7.5 (37). Stacked thylakoids were prepared for freeze-etching using the $2 \mathrm{mM}-\mathrm{MgCl}_{2}, 5 \mathrm{mM}$-tris, $\mathrm{pH} 7.6$ buffer of STAEHELin (37).

Freeze-etching was performed with a Balzers BAF301 device (Balzers AG, Liechtenstein) at a temperature of $-100^{\circ} \mathrm{C}$ for $1.5 \mathrm{~min}$ at a vacuum of $2 \times 10^{-6}$ torr or better. Specimens were frozen directly in liquid Freon 22 (with $30 \%$ glycerol for freeze-fracturing) without prior chemical fixation. All other procedures were as described in an earlier paper (32). Pictures are printed so that the direction of shadowing is from bottom to top, and all are from plants grown for 7 days in continuous white light.

\section{RESULTS}

\subsection{Normal thylakoid structure}

The four different membrane faces produced by freeze-fracturing of barley chloroplast thylakoids isolated from seedling leaves grown for 7 days in light are shown in Figure 1. The terminology of STAEHELIN (37) is used to distinguish between stacked (s) and unstacked $(u)$ regions of the endoplasmic (EFs and EFu) and protoplasmic (PFs and PFu) fracture faces.

The most easily recognisable face was the EFs, shown in Figure 2. This fracture face was characterised by a relatively high density of large particles on a flat, smooth background. The EFu face (Figure 3), which is continuous with the EFs face, contained fewer particles per square micron. These particles had a smaller average size, and were found on an undulating background containing numerous small pits.

The corresponding PF faces were readily distinguished from the EF faces due to the greater number of particles per unit area on PF faces. It was more difficult to distinguish between PFs and PFu faces than between stacked and unstacked regions of the EF face. The PFs face was flat and occasionally circular in outline and densely covered with small, uniformly sized particles in low relief from the surface (Figure 2). The PFu face (Figure 4) was characterised by a similar density of freeze-fracture particles, but their average size was slightly greater than those on the PFs face.

When stacked thylakoids were experimentally destacked in $5 \mathrm{~mm}$-tricine (37) the particles became randomly distributed by moving later.

\footnotetext{
Abbreviations: $E F=$ endoplasmic fracture; IEF = inner envelope endoplasmic fracture; IPF = inner envelope protoplasmic fracture; EFs $=$ endoplasmic fracture (stacked); EFu = endoplasmic fracture (unstacked); ES = endoplasmic surface; $\mathrm{OEF}=$ outer envelope endoplasmic fracture; OPF $=$ outer envelope protoplasmic fracture; $\mathrm{PF}=$ protoplasmic fracture; $\mathrm{PFs}=$ protoplasmic fracture (stacked); $\mathrm{PFu}=$ protoplasmic fracture (unstacked); S.D. = standard deviation; PS = protoplasmic surface; HEPES = N-(2-hydroxyethyl) -piperazine-N'-2-ethanesulphonic acid; $\mathrm{MES}=2(\mathrm{~N}$-morpholino)ethane sulphonic acid; $\mathrm{PIPES}=$ piperazine-N,N'-bis(2-ethane sulphonic acid)
} 


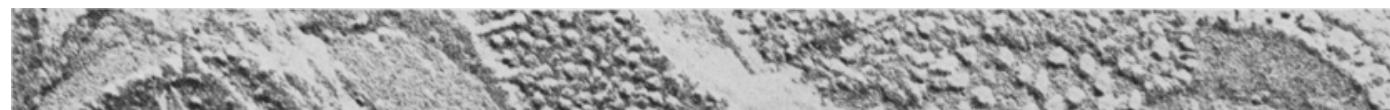

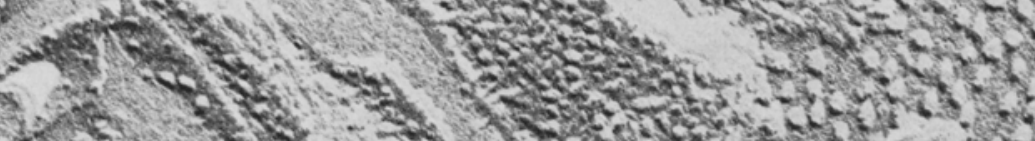

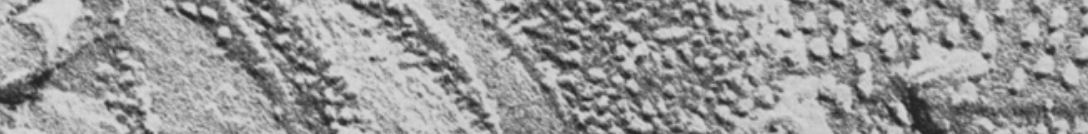

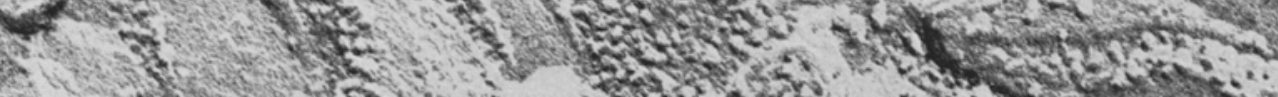

\section{If}

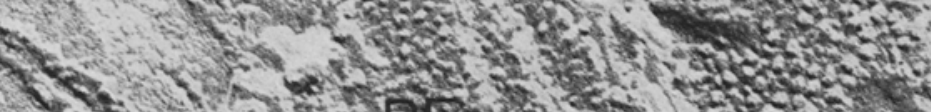

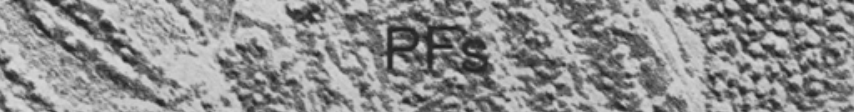

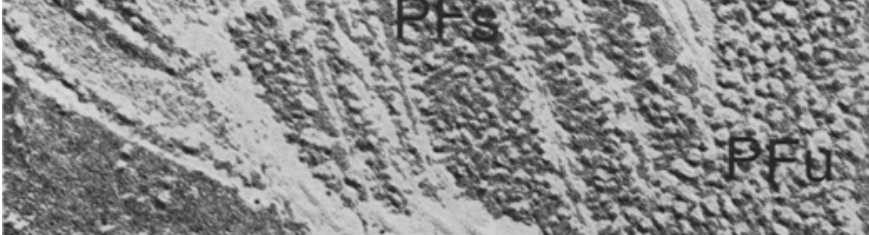

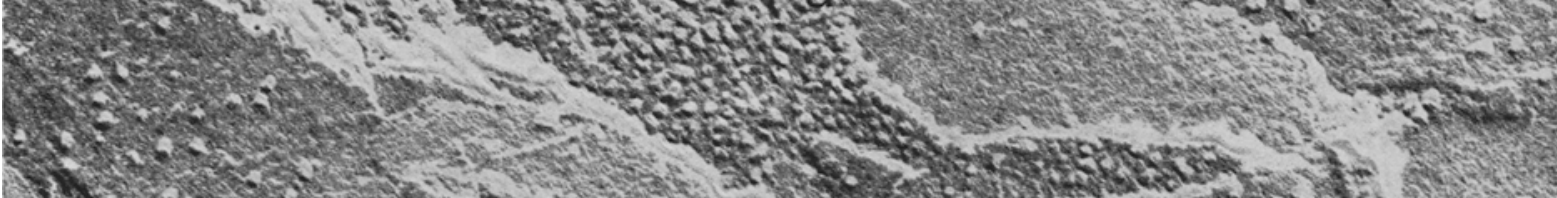

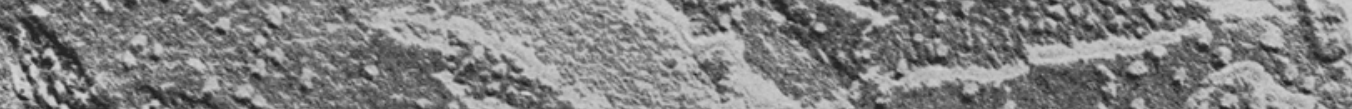

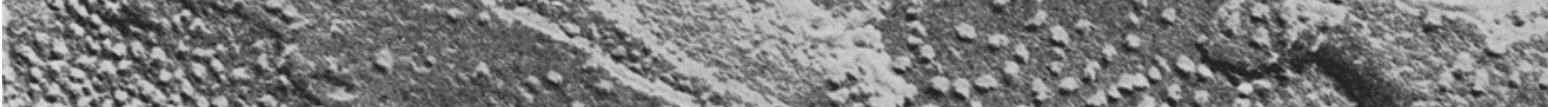

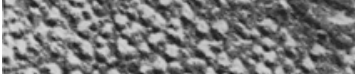

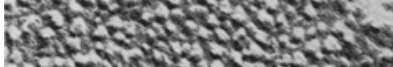

3 (1)

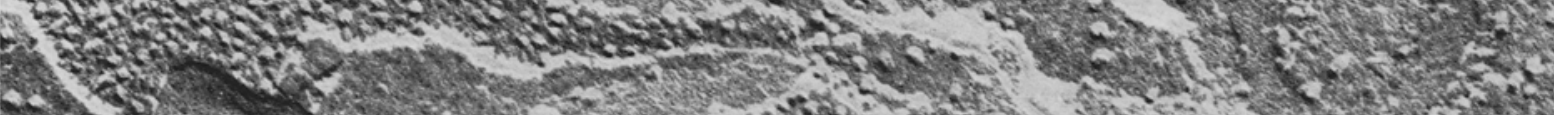

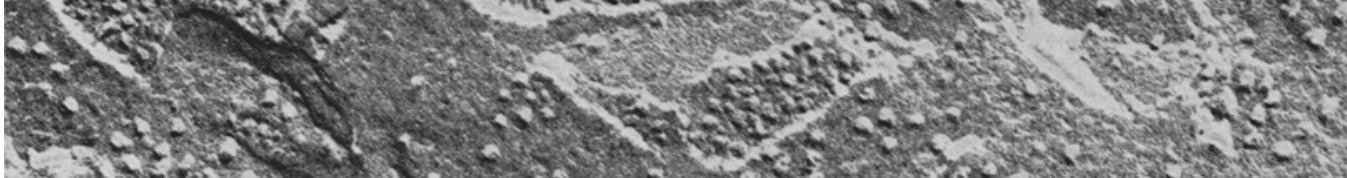

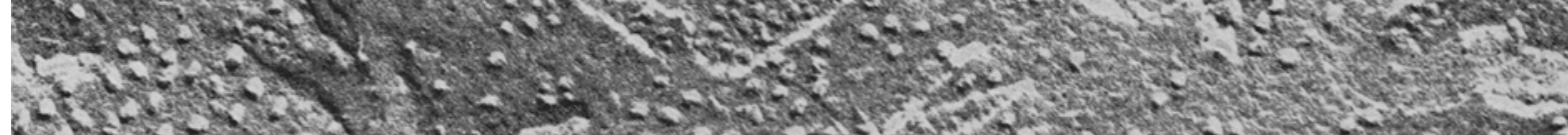

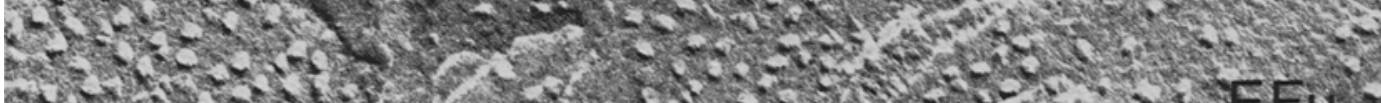

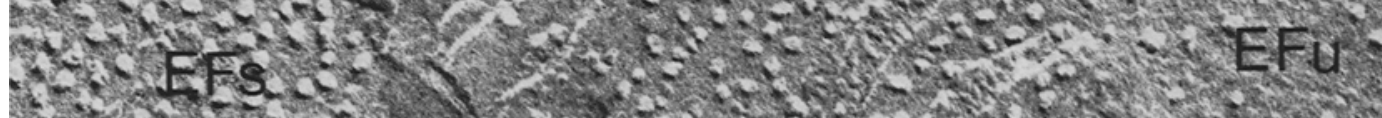

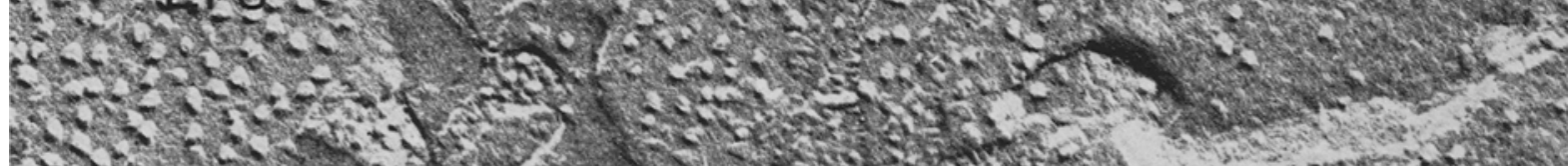

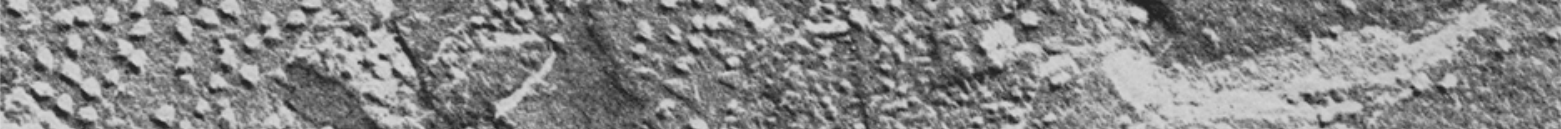

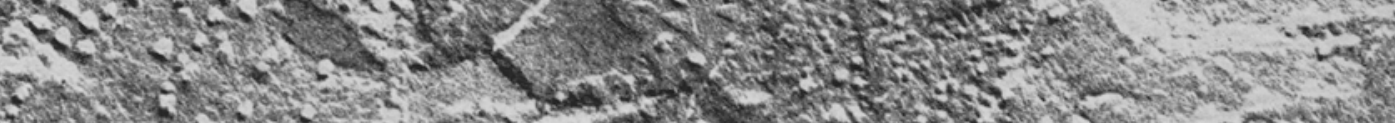

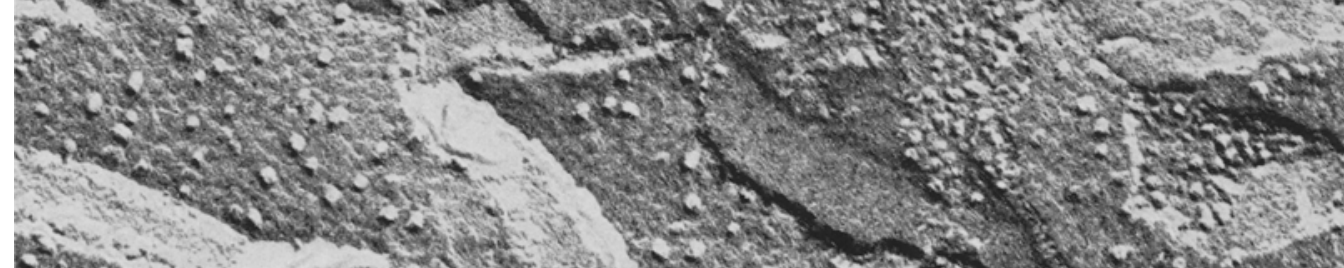

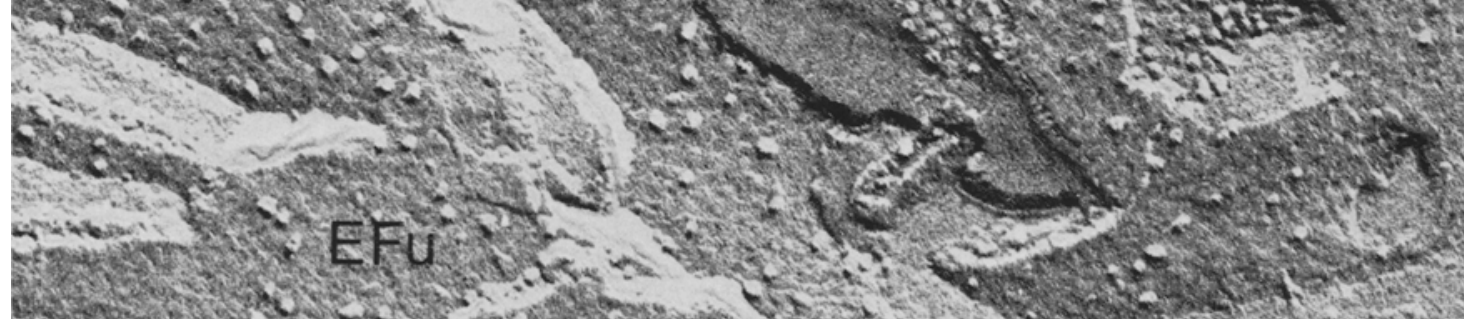

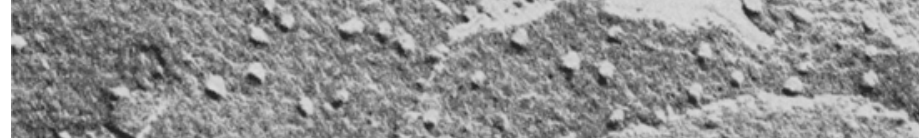




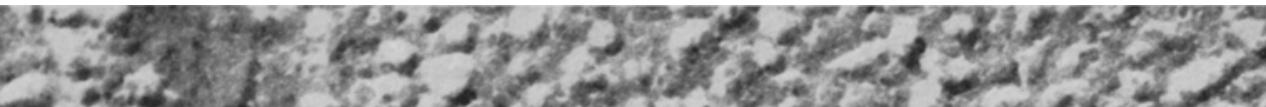

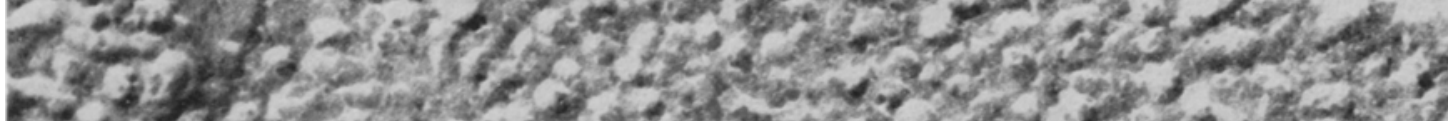

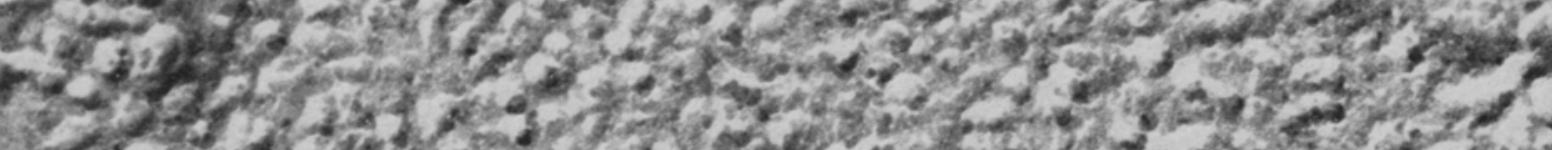

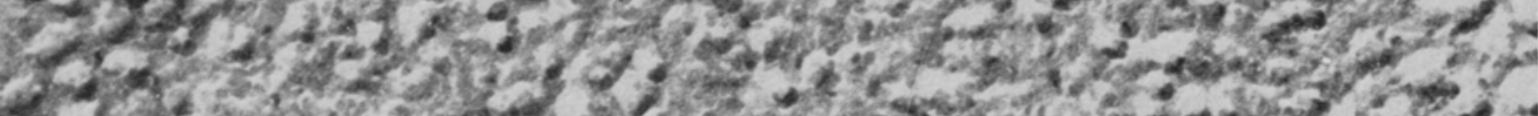

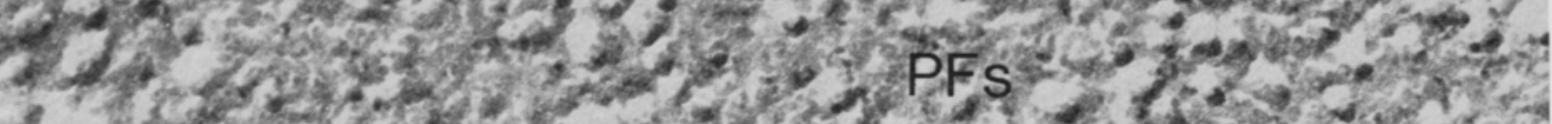

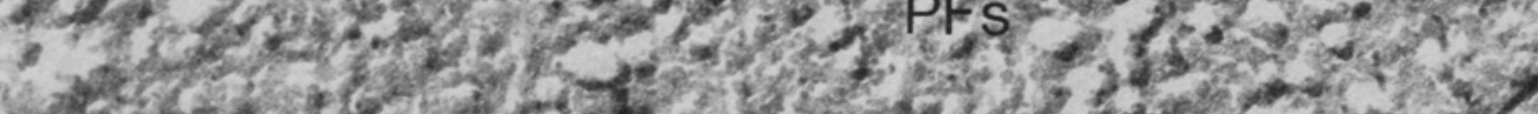

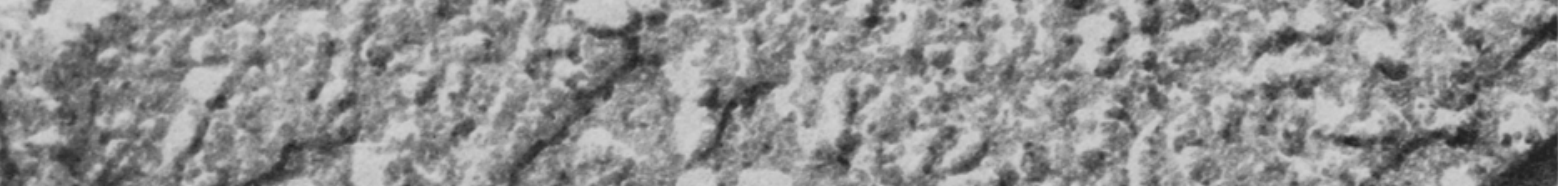

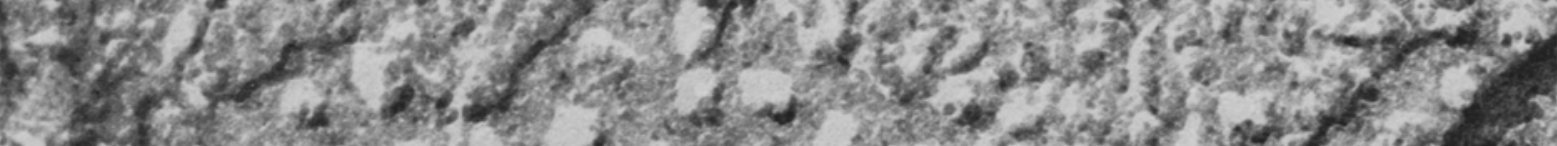

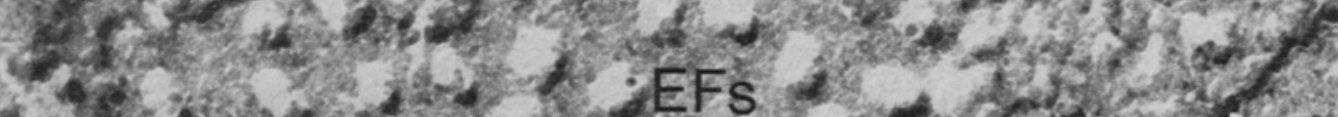

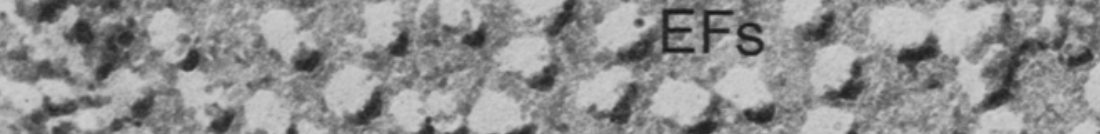

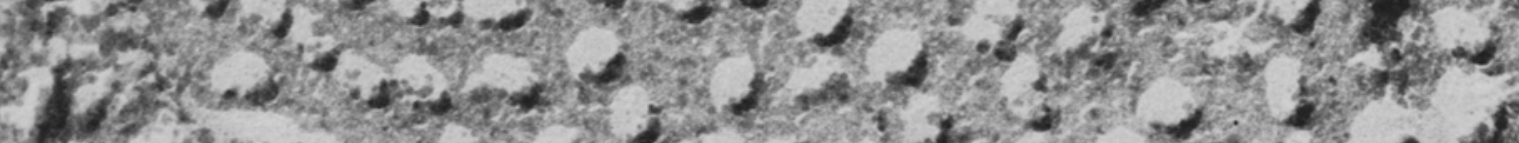

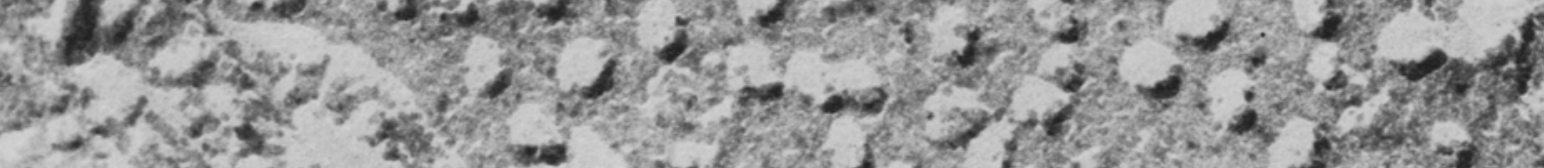

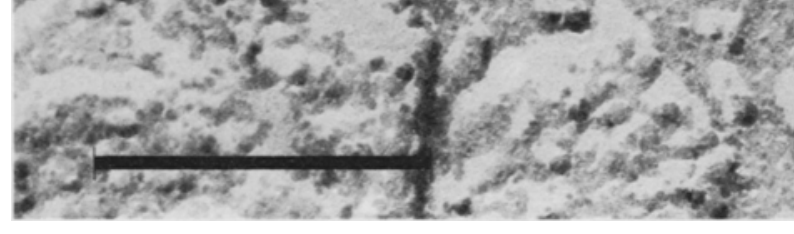

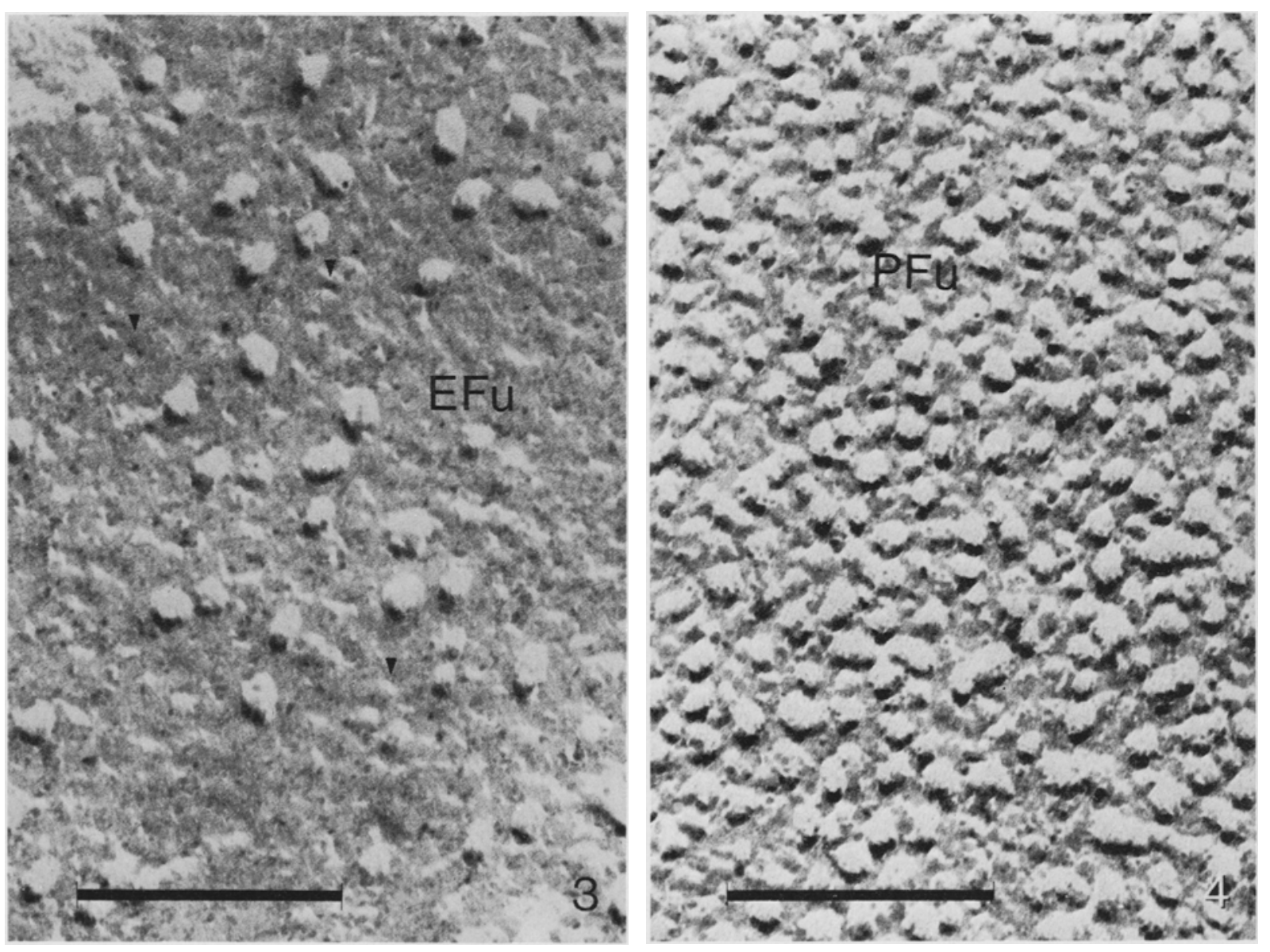


Figure 2. Higher magnification micrograph of the EFs face which has large particles on a smooth, flat background, and the closely appressed PFs face which is characterised by a high density of small particles. $\times 340,000$ $(\mathrm{Bar}=0.1 \mu \mathrm{m})$.

Figure 3. The EFu face has a low density of particles whose average size is smaller than those on the EFs face. The background contains small pits (arrowheads). $\times 340,000(B a r=0.1 \mu \mathrm{m})$.

Figure 4. The PFu face contains as many particles per square micron as the PFs face (Figure 2), but the average size of the particles is larger. $\times 340,000(\mathrm{Bar}=0.1 \mu \mathrm{m})$.

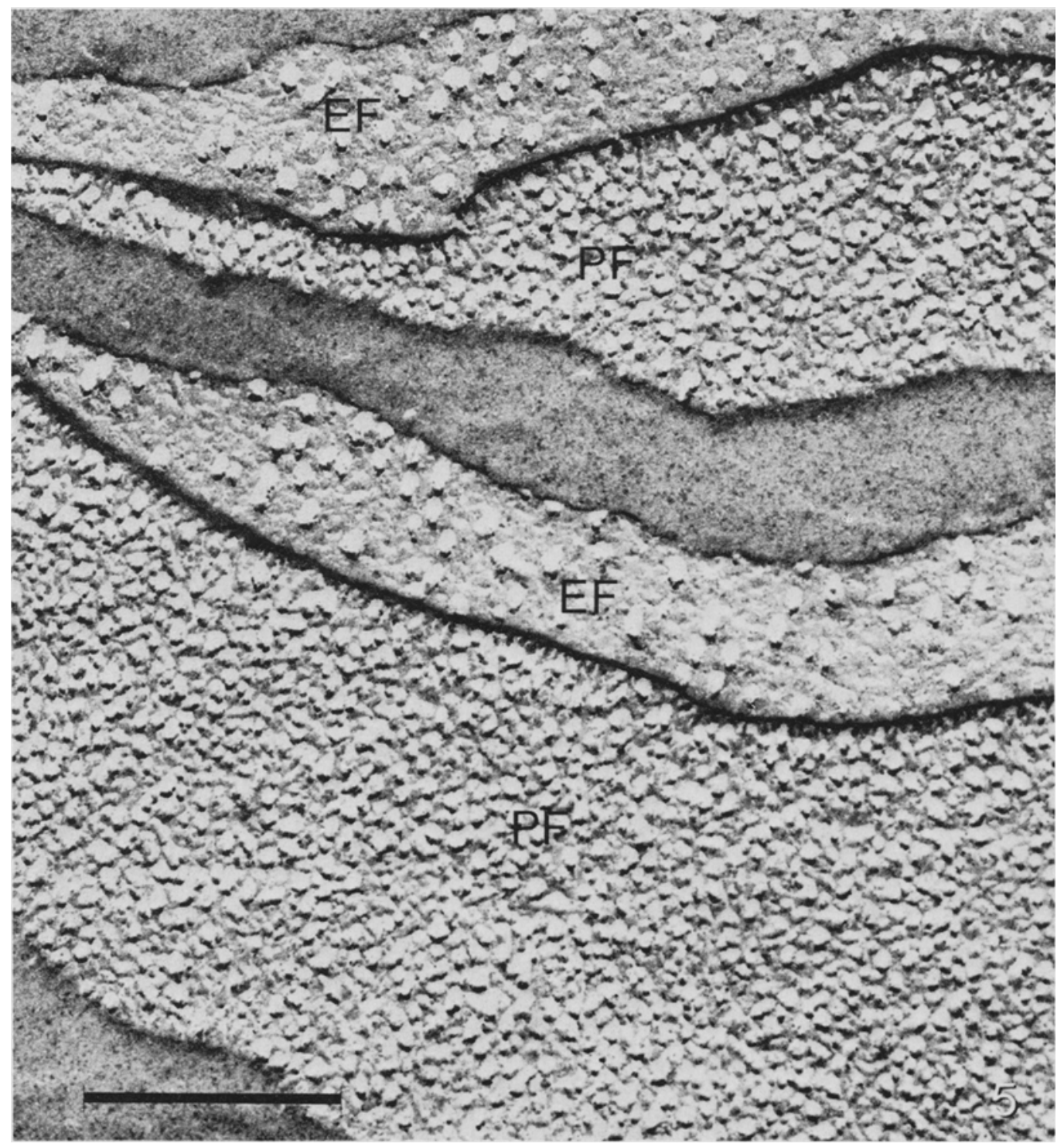

Figure 5. Chloroplast thylakoids destacked by $5 \mathrm{~mm}$-tricine, $\mathrm{pH} 7.5$ show a uniform distribution of particles over the EF and PF faces due to the lateral movement of particles within each face. $\times 170,000(\mathrm{Bar}=0.2 \mu \mathrm{m})$. 
Table I

Freeze-fracture particle densities of wild-type barley chloroplast thylakoids S.E. = standard error of the mean.

\begin{tabular}{llrr}
\hline Growth conditions & Face & No. $/ \mu \mathrm{m}^{2} \pm \mathrm{S} . \mathrm{E}$. & Area measured $\left(\mu \mathrm{m}^{2}\right)$ \\
\hline Six days in dark, & EFu & $389 \pm 10$ & 3.52 \\
24h in light & PFu & $4508 \pm 45$ & 1.10 \\
& EFs & $1445 \pm 11$ & 1.30 \\
Seven days in light & PFs & $4667 \pm 56$ & 0.56 \\
& EFu & $736 \pm 12$ & 4.06 \\
& PFu & $4378 \pm 36$ & 1.61 \\
& EFs & $1670 \pm 26$ & 1.66 \\
\hline
\end{tabular}

ally on each fracture face (EF and PF). Each face was therefore no longer differentiated into areas distinguishable by differences in the size or density of freeze-fracture particles (Figure 5, Tables III and IV).

The freeze-fracture characteristics of barley thylakoids were quantified by measuring the numbers of particles per square micron and the size distribution of the particle widths for each of the fracture faces. These results are presented in Tables I and II and in Figure 6 for chloroplasts isolated from seedling leaves grown for 6 days in darkness and $24 \mathrm{~h}$ in light, or for 7 days in continuous white light. All four fracture faces can be distinguished from one another on the basis of their average particle size (Table II) and particle size distribution (Figure 6). It is more convenient, however, to identify the different faces visually by the number of particles per square micron (except to distinguish between PFs and PFu). The major difference between the freeze-fracture appearance of thylakoids greened or 1 or 7 days was in the lower average size and density of the particles on the EFu face of thylakoids greened for only 1 day (Tables I and II, Figure 6).

Freeze-etching of stacked thylakoids from plants greened for 7 days revealed the inner and outer membrane surfaces, designated ES and PS respectively (22). The endoplasmic surface of barley thylakoids was differentiated into stacked (ESs) and unstacked (ESu) regions. Stacked regions were usually circular areas slightly raised above the level of unstacked membrane regions, and were covered with numerous particles on a smooth surface (Figure 7). These particles were composed of smaller subunits, usually four, and were asymmetric in

\section{Table II}

Freeze-fracture particle sizes of wild-type barley chloroplast thylakoids. S.D. = standard deviation of population size distribution.

\begin{tabular}{llrc}
\hline Growth conditions & Face & Average size \pm S.D. $(\dot{A})$ & No. counted \\
\hline Six days in dark, & EFu & $100.2 \pm 23.5$ & 1000 \\
24h in light & PFu & $97.5 \pm 22.0$ & 1000 \\
& EFs & $138.4 \pm 26.2$ & 1000 \\
Seven days in light & PFs & $79.9 \pm 15.9$ & 1000 \\
& EFu & $116.5 \pm 26.8$ & 1000 \\
& PFu & $100.6 \pm 23.0$ & 1000 \\
& EFs & $144.1 \pm 28.7$ & 1000 \\
& PFs & $81.2 \pm 13.3$ & 1000 \\
\hline
\end{tabular}



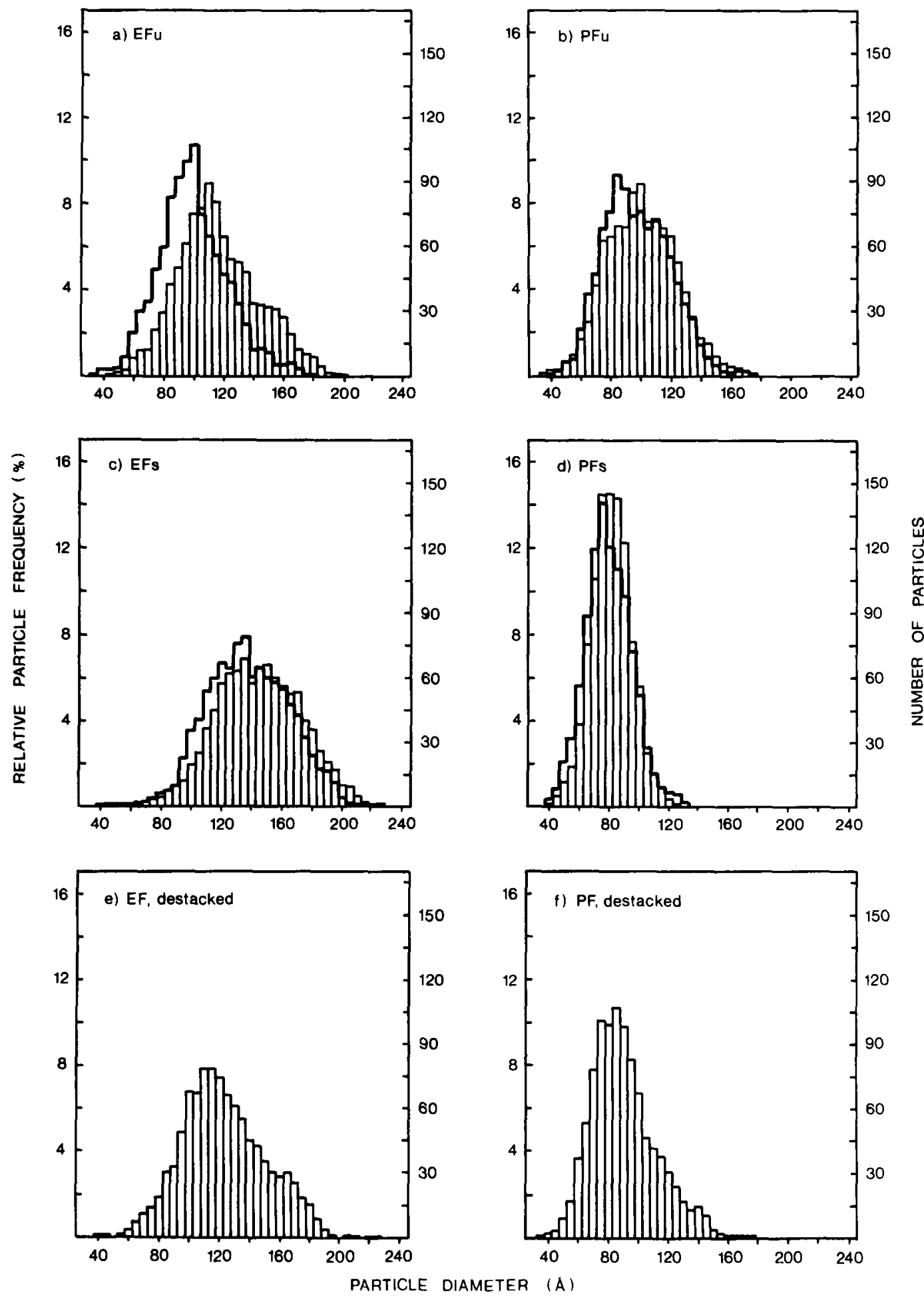

Figure 6. Computer-drawn histogram plots of the size distributions of the particles on fracture faces of barley chloroplast thylakoids. Measurements and statistical treatment were as described in (32). The size distributions of plants grown in the dark for 6 days and 1 day in the light (heavy lines) are superimposed over the corresponding histogram for plants grown for 7 days in the light. Numerical values are presented in Table II. 


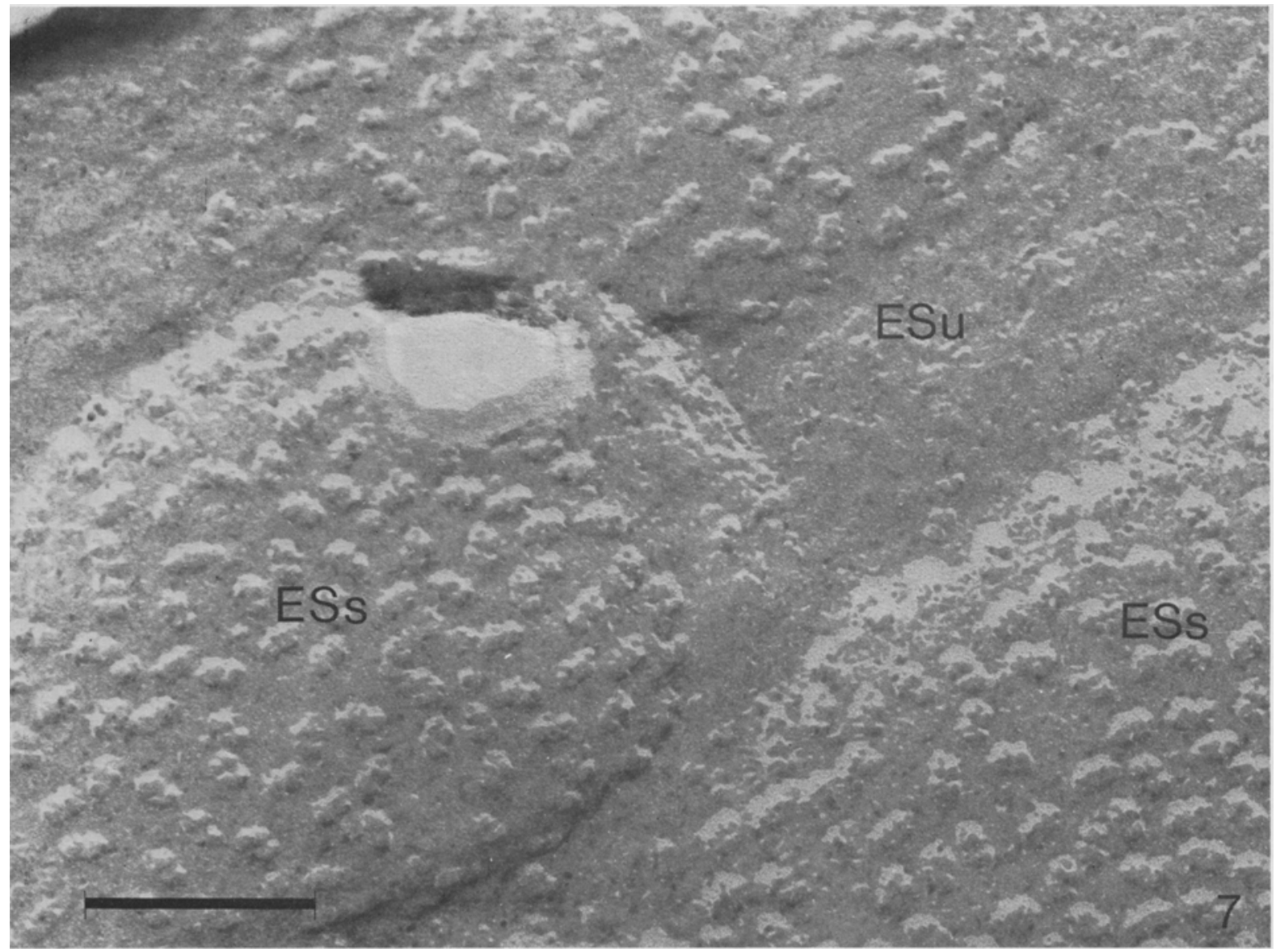

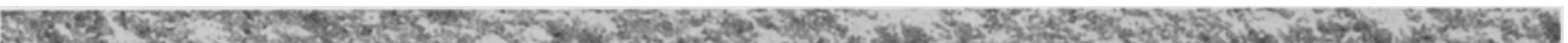

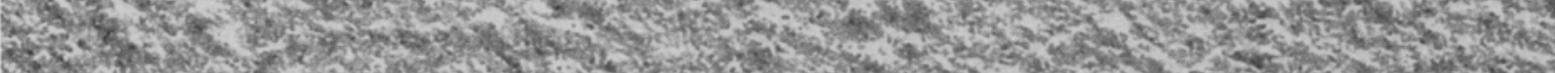

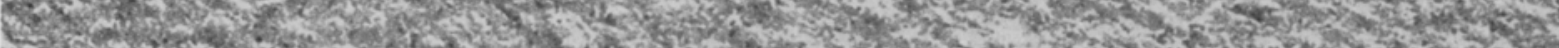

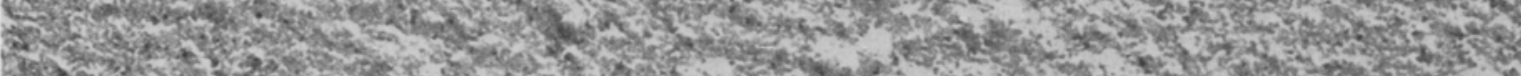

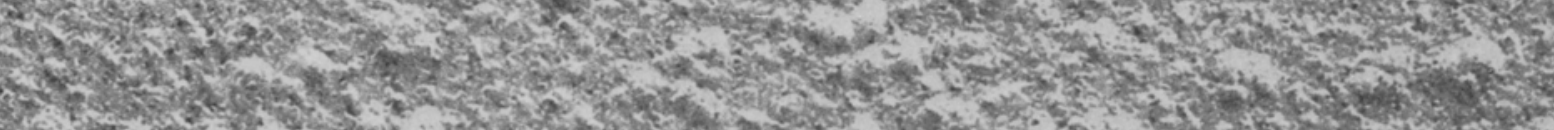

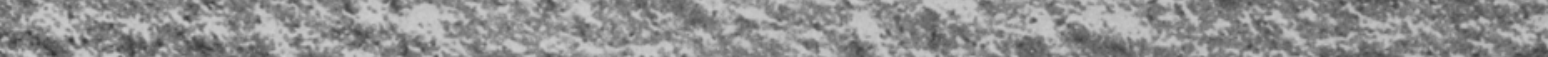

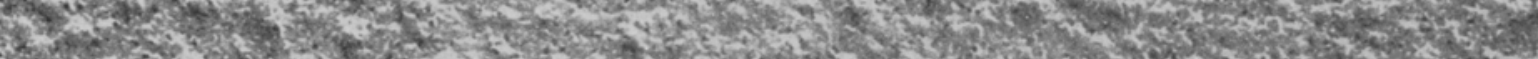

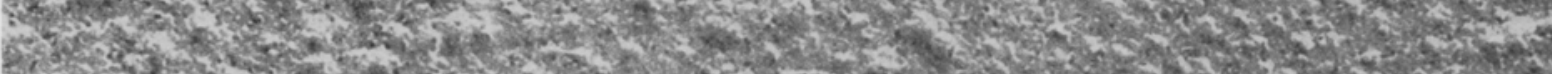

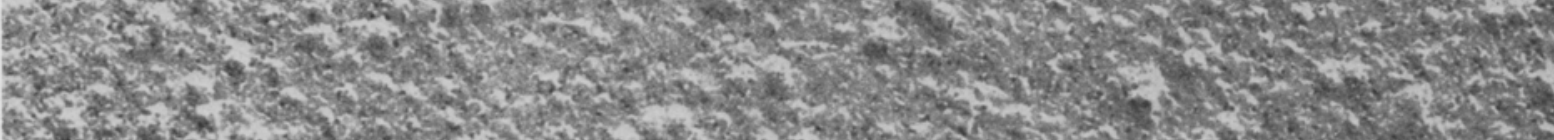

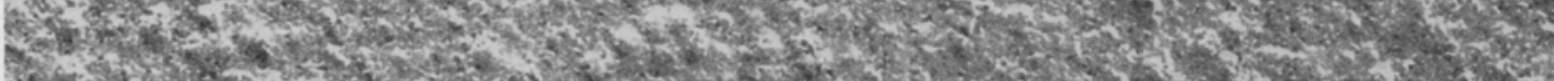

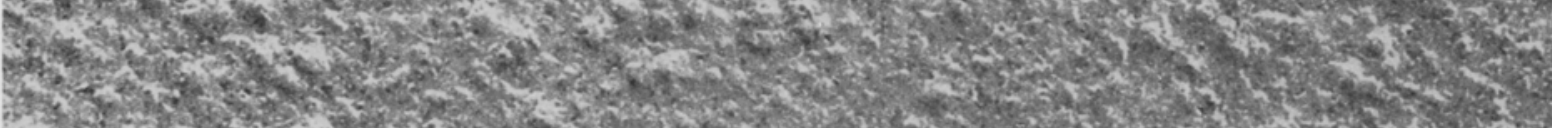

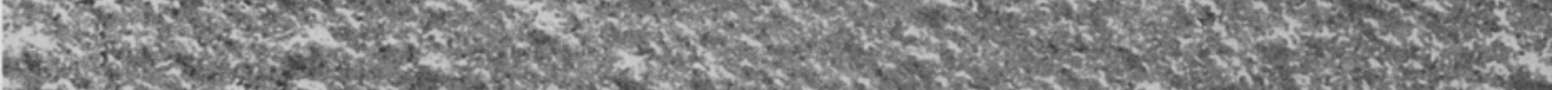

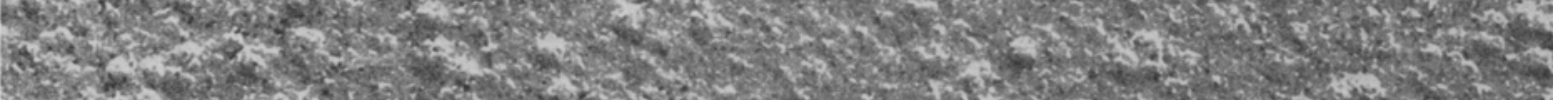

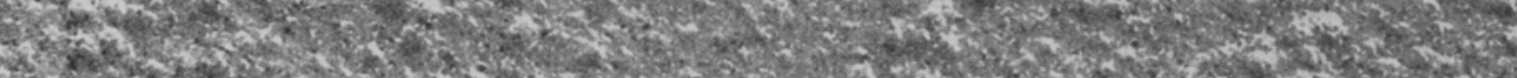

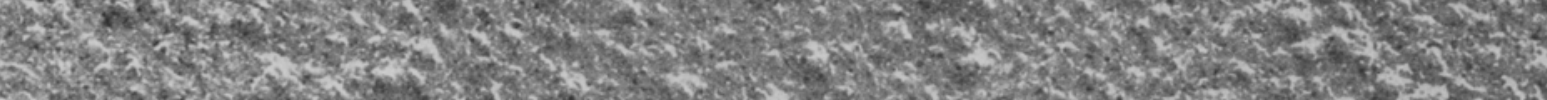

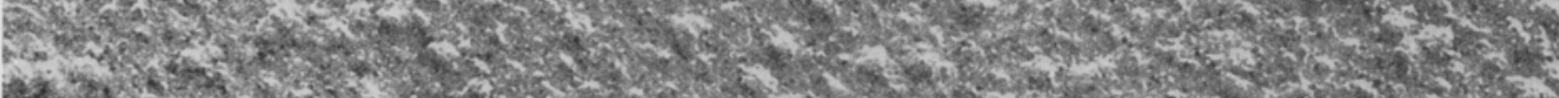

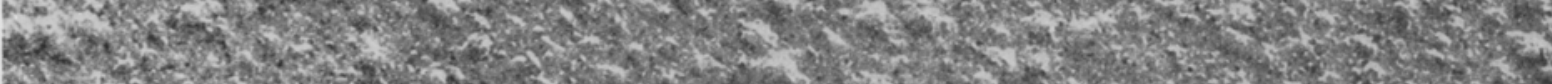

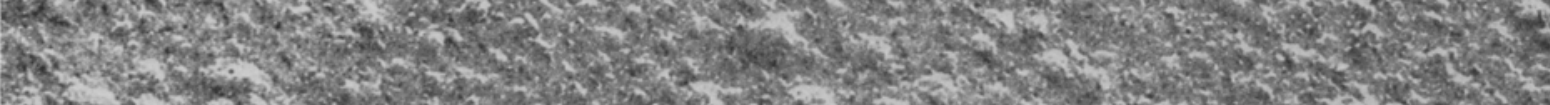
F.

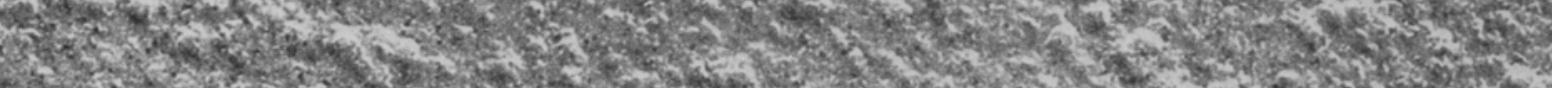
6.

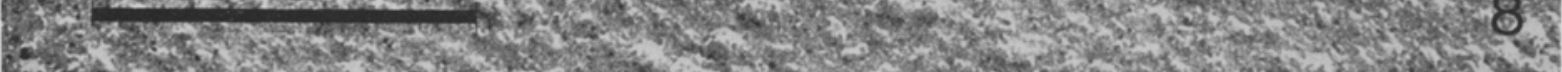



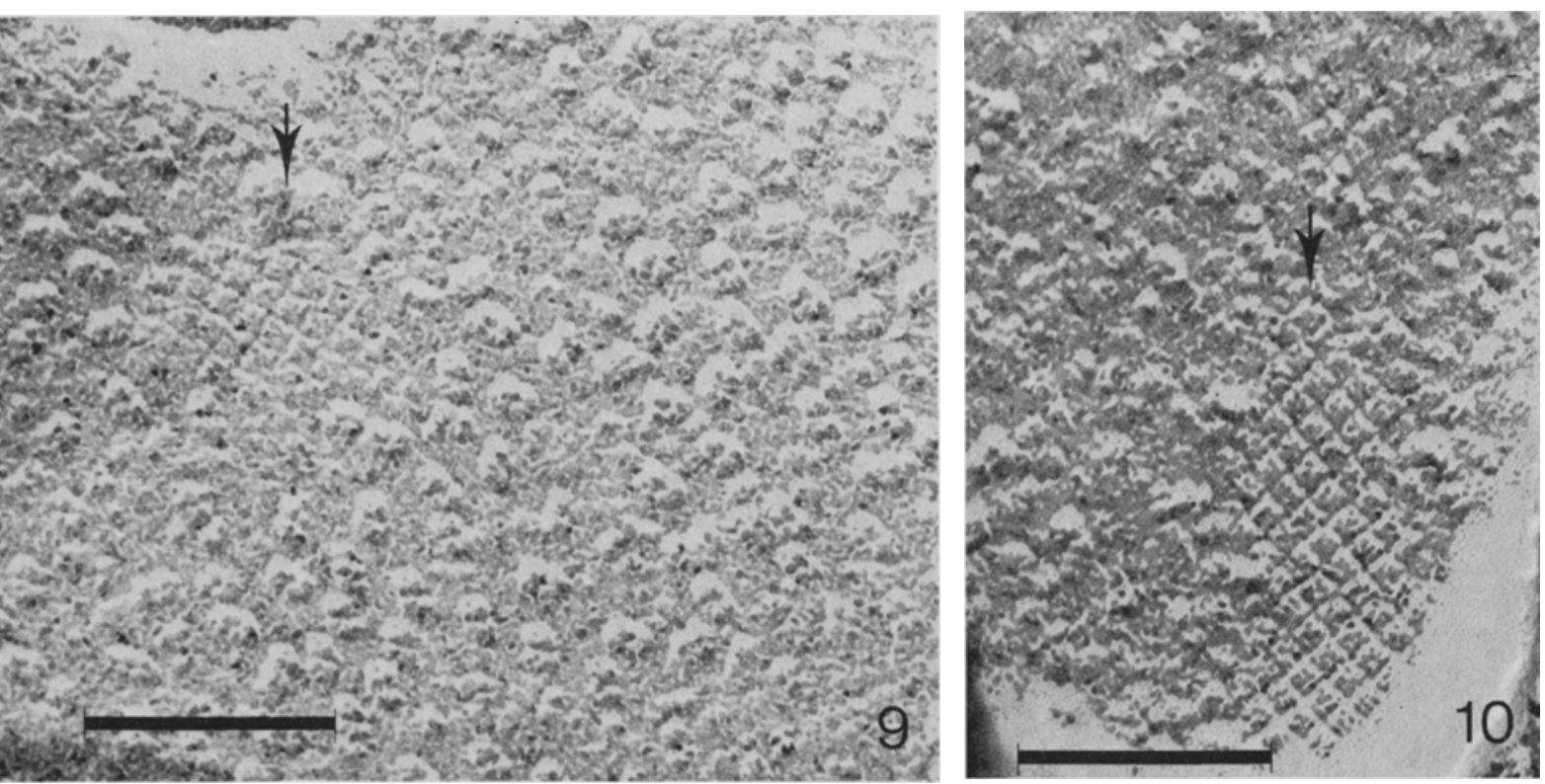

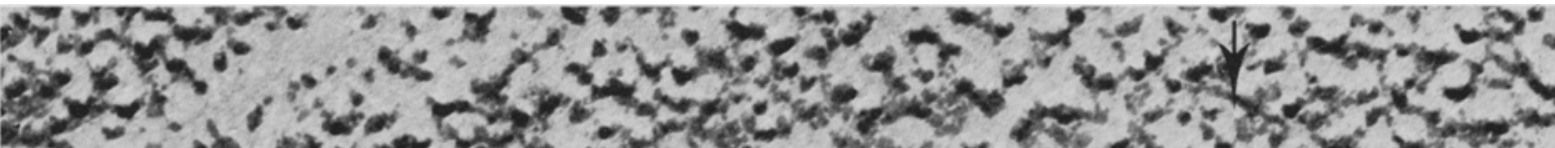

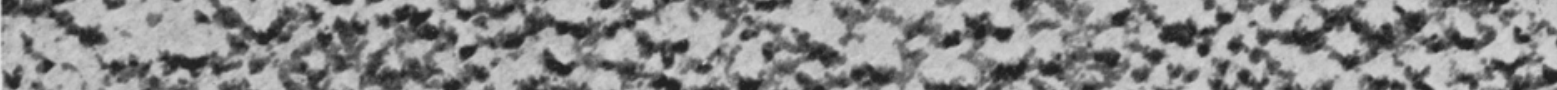

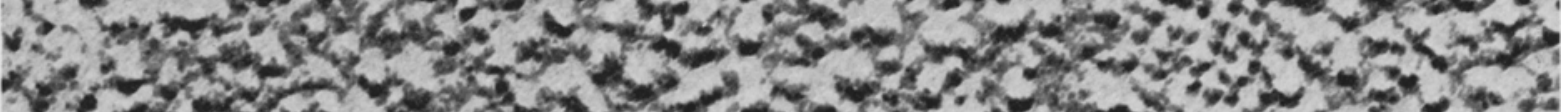

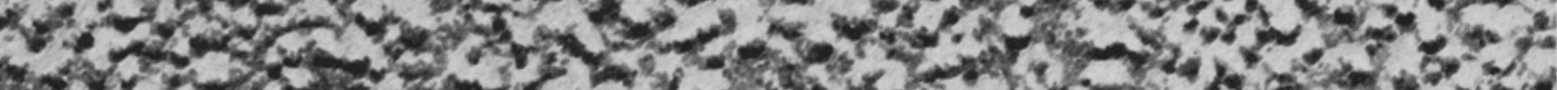

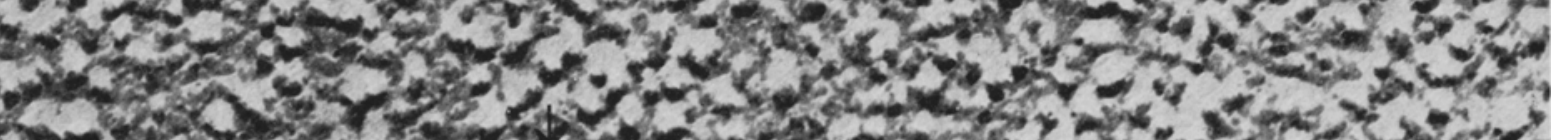

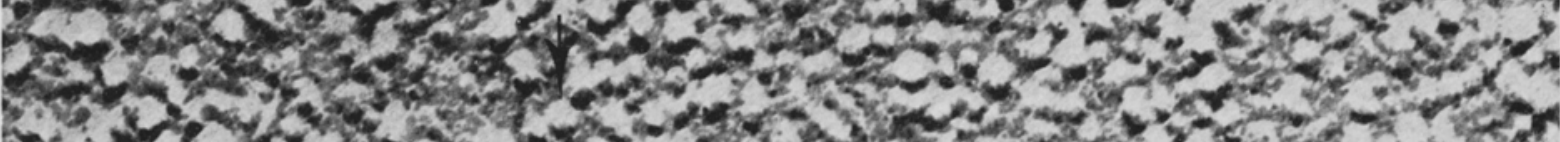

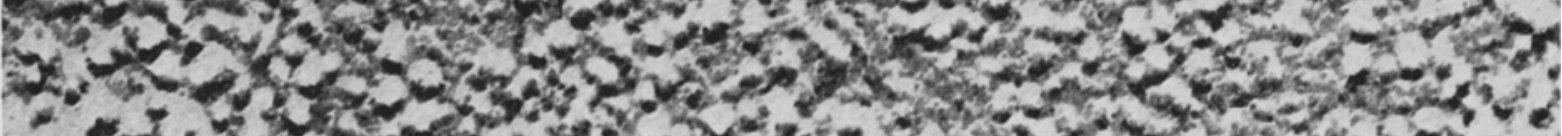

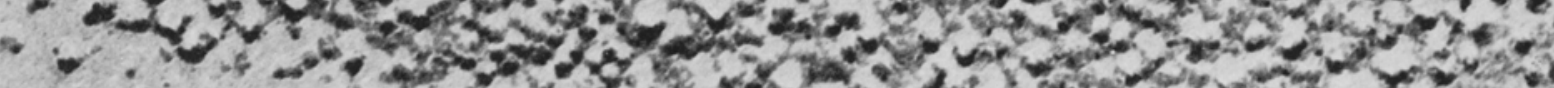
An 3. 


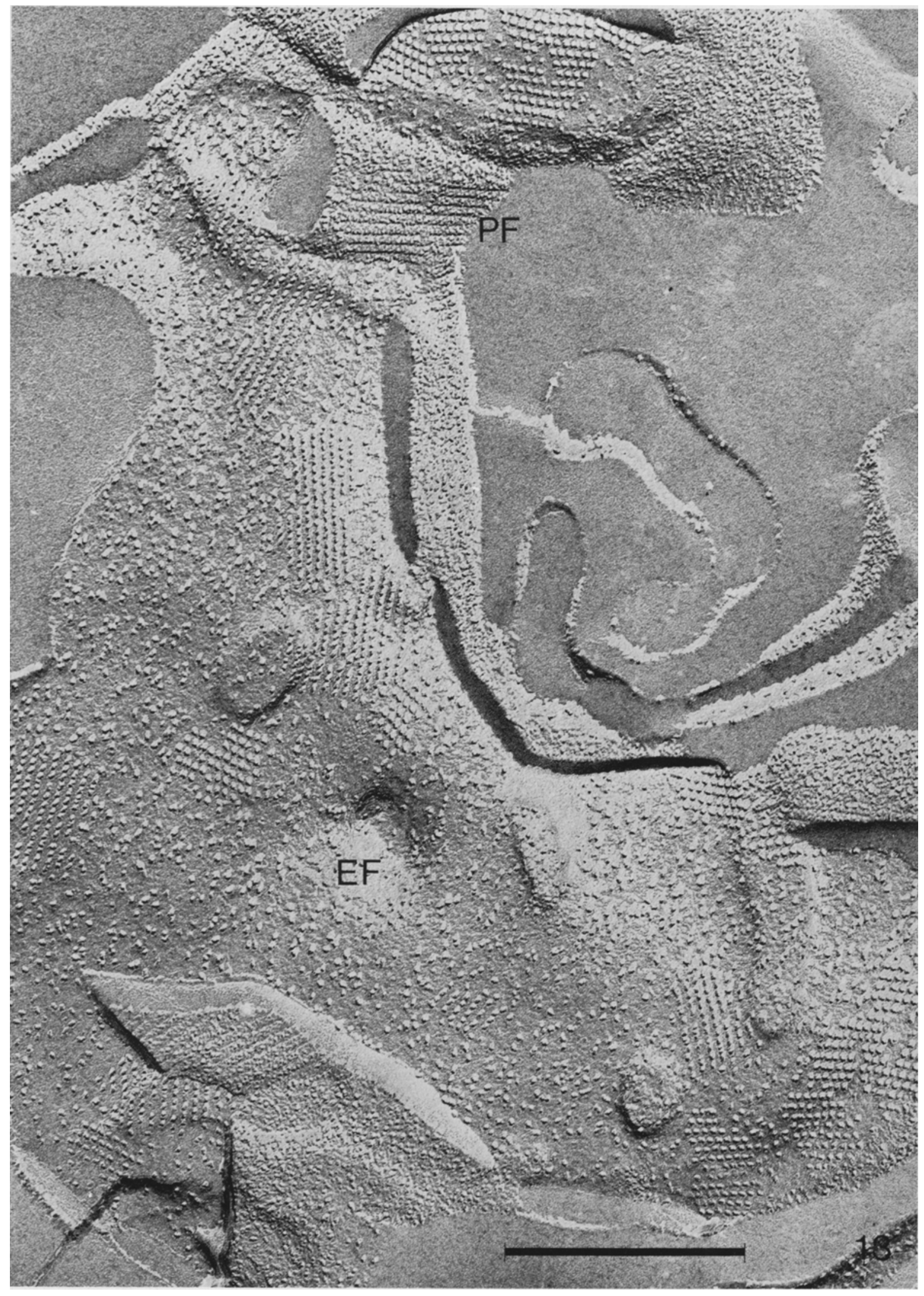


Figure 7. Freeze-etching reveals the inner (endoplasmic) thylakoid surface which consists of raised circular regions (ESs) containing numerous particles composed of subunits, corresponding to stacked thylakoid regions, as well as areas $(\mathrm{ESu})$ where particles are very difficult to distinguish on a rough surface and which correspond to unstacked region of the thylakoid. $\times 290,000(\mathrm{Bar}=0.1 \mu \mathrm{m})$.

Figure 8. The outer (protoplasmic) surface of the thylakoid is covered with large and small particles, as shown in this micrograph of the PS of destacked barley thylakoids. $\times 195,000(\mathrm{Bar}=0.2 \mu \mathrm{m})$.

Figures 9 and 10. A small number of square lattices of particles of low surface relief are found on the ESu, and more commonly on the ES of destacked (5mM-tricine) thylakoids (Figure 9) and array-induced (5mM-HEPES) thylakoids (Figure 10). Components of the lattice seem to have a fine structure (Figure 10) and other particles are excluded from the lattice. $\times 260,000(\mathrm{Bar}=0.1 \mu \mathrm{m})$.

Figure 11. Square lattices of small particles (arrows) are sometimes seen on the PF face of array-induced thylakoids. $\times 260,000(B a r=0.1 \mu \mathrm{m})$.

Figure 12. The clusters of small pits (arrows) in the EF face of array-induced thylakoids may represent the complementary structure to that shown on the PF face in Figure 11. $\times 260,000(\mathrm{Bar}=0.1 \mu \mathrm{m})$.

Figure 13. Low magnification electron micrograph of freeze-fractured barley chloroplast thylakoids after incubation in $25 \mathrm{mM}$-HEPES, which induces extensive formation of arrays on both EF and FP faces. $\times 84,000$ (Bar $=$ $0.5 \mu \mathrm{m})$.

shape, although they appeared to be remarkably uniform in size. The adjacent ESu surfaces were less smooth, and it was difficult to distinguish individual particles (Figure 7). The protoplasmic surface is similarly differentiated into stacked and unstacked regions, but the stacked surfaces are appressed together and cannot be examined under normal conditions (38). The unstacked protoplasmic surface of barley chloroplast thylakoids was rough and covered with numerous large and small particles.

Destacking of thylakoids in 5mM-tricine resulted in the randomisation of the distribution of ES particles over the entire surface and a lowering of the particle density on the PS, as reported for spinach (22). As noted by MILLER et al. (19) the large particles on the protoplasmic surface of barley thylakoids (Figure 8) are smaller and less dense than those of spinach. An unusual feature of the ESu, more commonly found on the destacked ES, was the presence of small areas of closely packed square particles of low surface relief (Figures 9 and 10). The average centre-to-centre distance between particles was $124.1 \pm 3 \AA$ ( \pm S.D.). Possible corresponding particle lattices were found on the PF face of

\section{Table III}

Effect of destacking and array formation on freeze-fracture particle densities of 7-day old wild-type barley chloroplast thylakoids. S.E. = standard error of the mean.

\begin{tabular}{llcc}
\hline Treatment & Face & $\mathrm{No} / \mu \mathrm{m}^{2} \pm \mathrm{S} . \mathrm{E}$. & Area measured $\left(\mu \mathrm{m}^{2}\right)$ \\
\hline Destacking in & EF & $1151 \pm 12$ & 3.52 \\
5mM-tricine & $\mathrm{PF}$ & $4651 \pm 32$ & 1.50 \\
Array induction & EF unarrayed & $822 \pm 6$ & 9.14 \\
in 25mM-HEPES & EF arrayed & $2344 \pm 16$ & 2.10 \\
& PF arrayed & $6401 \pm 74$ & 0.24 \\
\hline
\end{tabular}




\section{Table IV}

Effect of destacking and array formation on freeze-fracture particle size of 7-day old wild-type barley chloroplast thylakoids. (Value in parentheses is the angle between the directions of shadowing and the orientation of the array). S.D. = standard deviation of population size distribution.

\begin{tabular}{llrr}
\hline Treatment & Face & Average size \pm S.D. $(\dot{A})$ & No. counted \\
\hline Destacking in & EF & $123.1 \pm 27.7$ & 1000 \\
5mM-tricine & PF & $90.2 \pm 21.6$ & 1000 \\
Array induction & EF unarrayed & $96.4 \pm 24.6$ & 1000 \\
in 25mM-HEPES & EF arrayed $\left(-20^{\circ}\right)$ & $102.2 \pm 14.9$ & 580 \\
& EF arrayed $\left(0^{\circ}\right)$ & $106.2 \pm 13.7$ & 1000 \\
& EF arrayed $\left(+30^{\circ}\right)$ & $144.3 \pm 20.9$ & 640 \\
& EF arrayed $\left(+70^{\circ}\right)$ & $175.5 \pm 25.5$ & 500 \\
& EF arrayed $\left(+90^{\circ}\right)$ & $161.5 \pm 23.5$ & 500 \\
& PF arrayed & $70.0 \pm 13.3$ & 700 \\
\hline
\end{tabular}

destacked thylakoids (Figure 11) and arrays of pits on the EF face (Figure 12), as also reported for spinach (37).

\subsection{Thylakoids with particle arrays}

Regular arrays of EFs and PFs particles were occasionally seen in some preparations of barley thylakoids (33). It was found, however, that a high frequency of such arrays was induced during the purification of wild-type barley thylakoids (17). Subsequent experiments established that simply incubating barley thylakoids in $25 \mathrm{mM}$-HEPES, pH 7.5 was sufficient to induce extensive array formation on both $E F$ and $\mathrm{PF}$ faces (Figure 13). It was found that arrays were formed after $1-2 \mathrm{~h}$ incubation at $0^{\circ} \mathrm{C}$ or at room temperature in HEPES concentrations ranging from $1-25 \mathrm{mM}$ and $\mathrm{pH}$ 's between 5 and 9. At $100 \mathrm{~mm}$ or higher, very few arrays were found, and when $2 \mathrm{mM}-\mathrm{MgCl}_{2}$ was added, be- fore or after incubation with 25mM-HEPES, $\mathrm{pH}$ 7.5 arrays were rarely found. Other buffers found to be effective in inducing array formation (at 25mM, pH 7.5) were PIPES, MES, tricine, and tris. Phosphate buffer under similar conditions was not effective. Unfortunately, conditions which induced arrays in destacked barley thylakoids were not effective with thylakoids of spinach, maize, tobacco, pea, bean and pine leaves.

Measurements of the density of particles in non-arrayed areas on EF faces of membranes containing arrays yielded a value lower than that found for the EF face of destacked thylakoids (Table III). The average size (Table IV) and size distribution (Figure 16 of these particles were also smaller than the corresponding values of destacked EF particles. Correspondingly, the particle density of arrayed EF particles was about twice as high as that determined for the destacked EF face (Table III).

Figure 14. Enlargement of two arrays on the EF face that are oriented at different angles (arrows) with respect to the direction of shadowing. Note the uniformity of particles widths within each array, although there are irregularities (arrowheads), and the difference in particle width between the two arrays. The average size of particles not in arrays is smaller than the average size of all particles on the destacked EF face. $\times 260,000(\mathrm{Bar}=0.1 \mu \mathrm{m})$.

Figure 15. Arrays found on the complementary PF face consisted of double rows of particles separated by deep grooves (arrows). The spacing between grooves was the same $(239.8 \pm 5.0 \AA$, maximum $=248.4 \AA)$ as between the widely spaced rows in EF arrays $(235.8 \pm 7.0 \mathrm{~A}$, maximum $=247.5 \mathrm{~A})$. Particles in $\mathrm{PF}$ arrays were smaller and more densely packed than those found on the destacked PF face. $\times 260,000(\mathrm{Bar}=0.1 \mu \mathrm{m})$. 


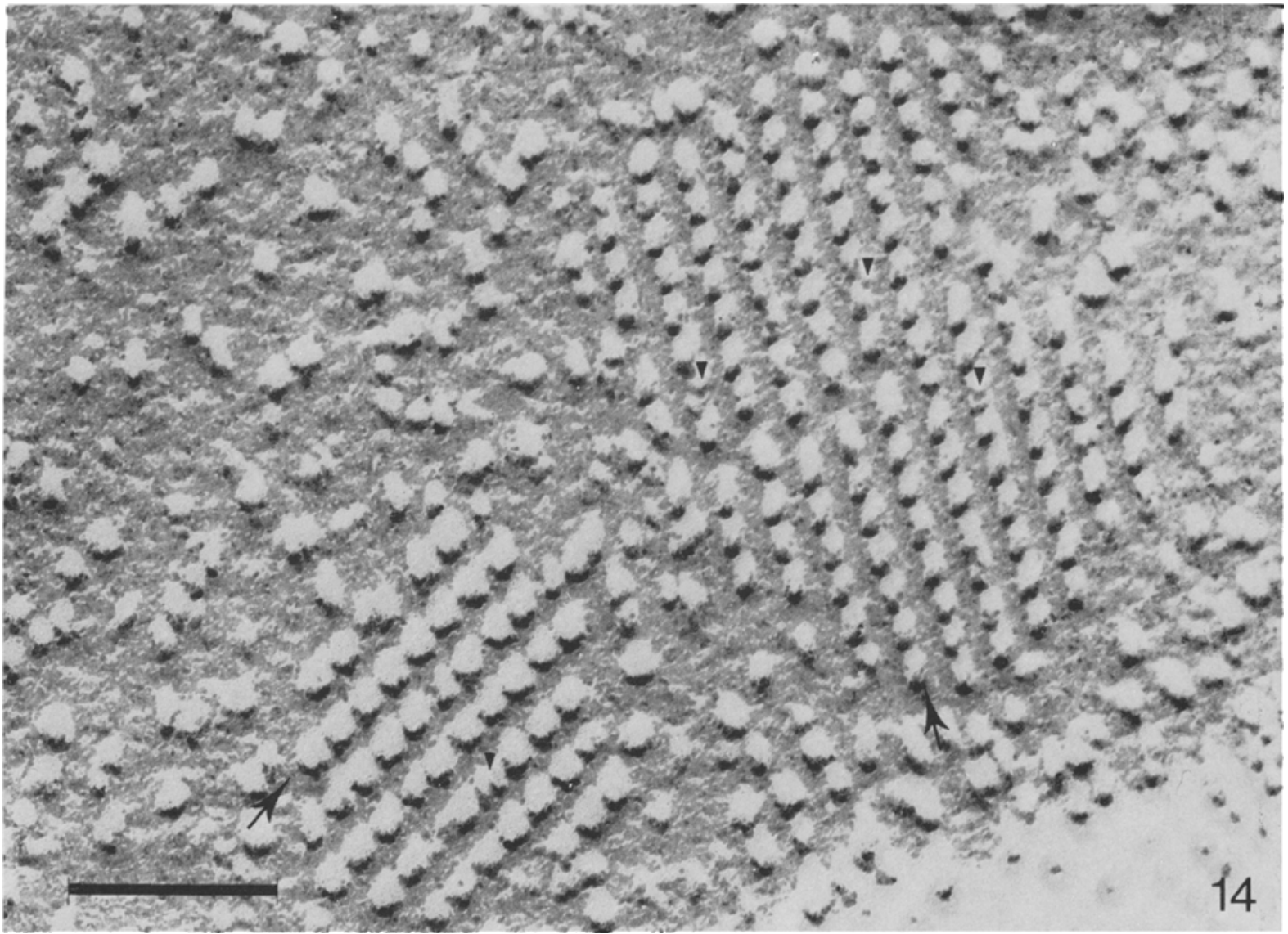

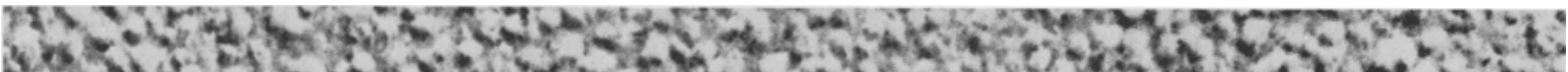
3.6.

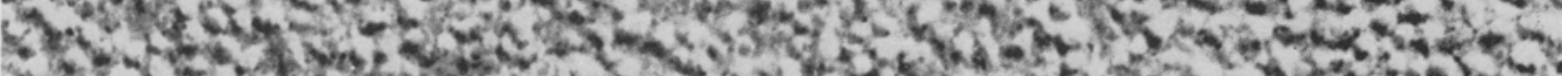

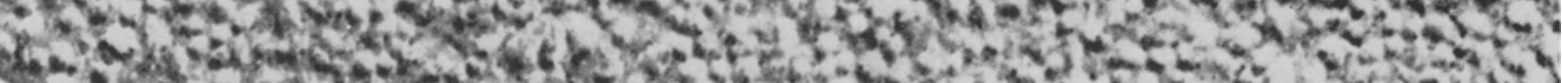

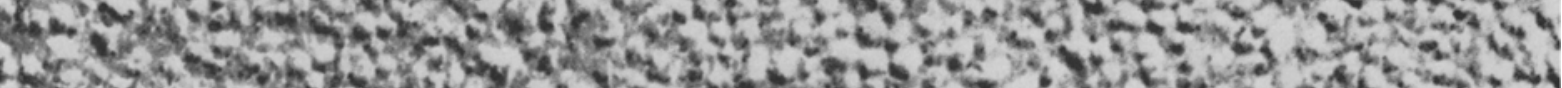

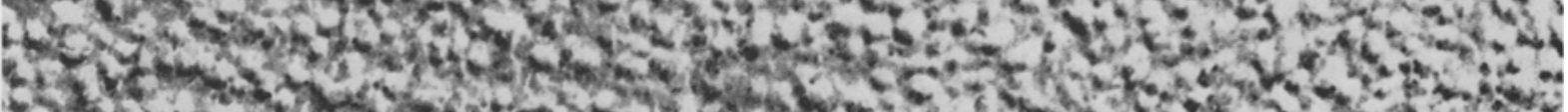

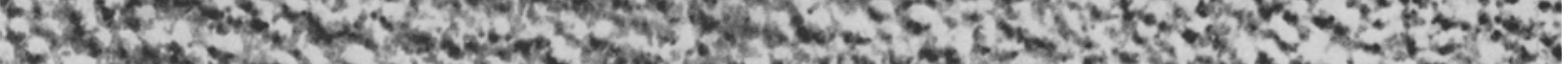

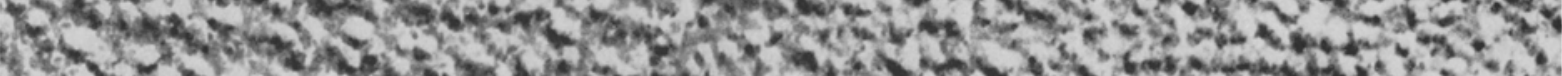
360.7 .

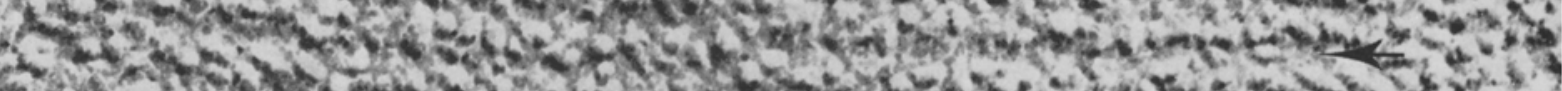

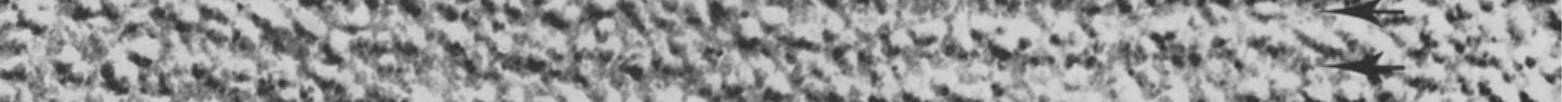

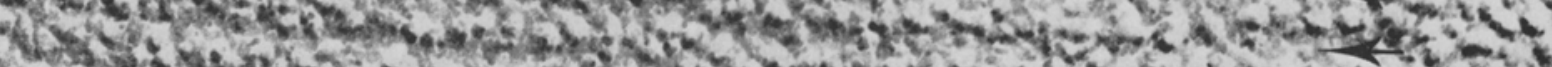

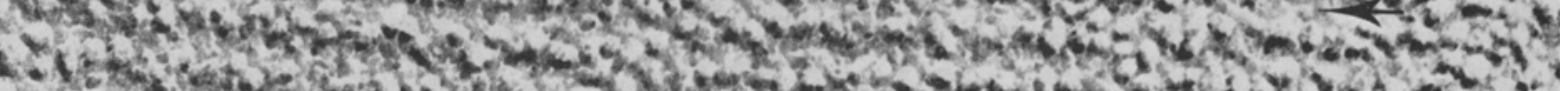

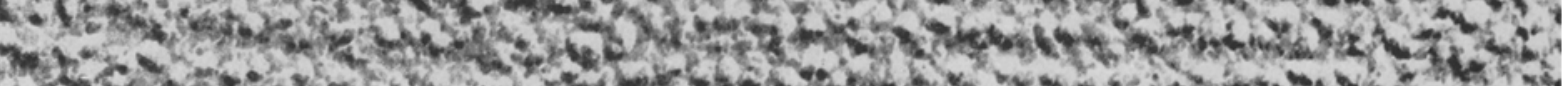

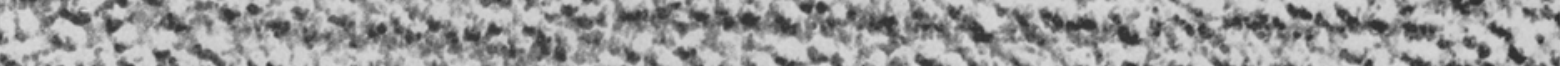

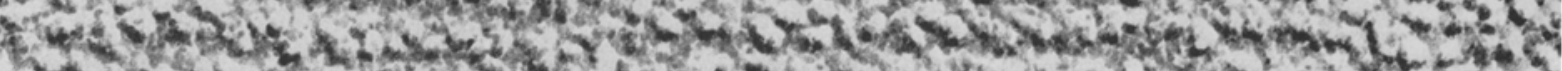

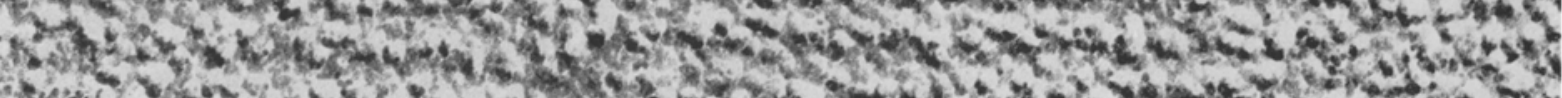

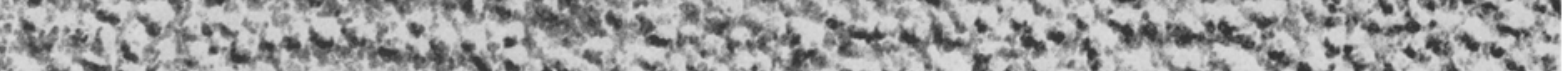

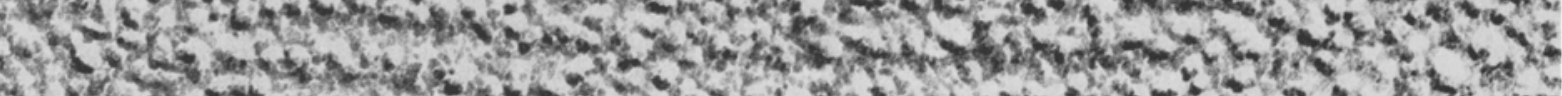

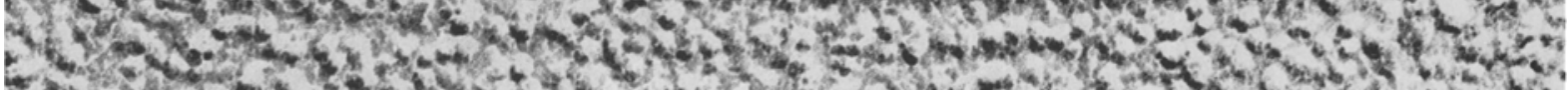

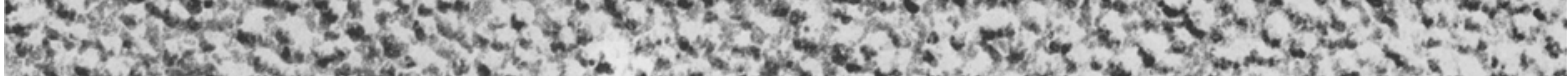

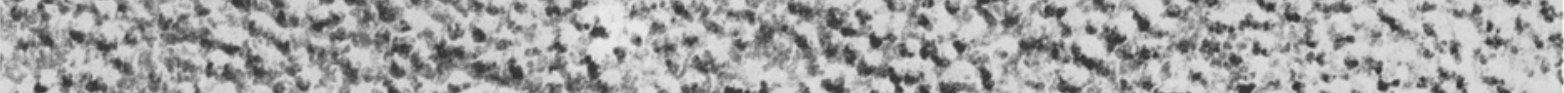

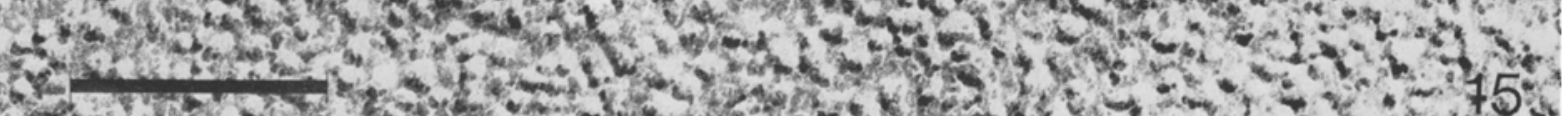

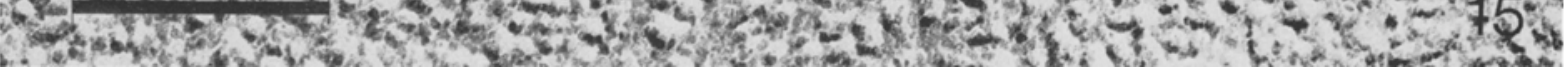




\section{J. SIMPSON: Freeze-fracture of barley chloroplast membranes}
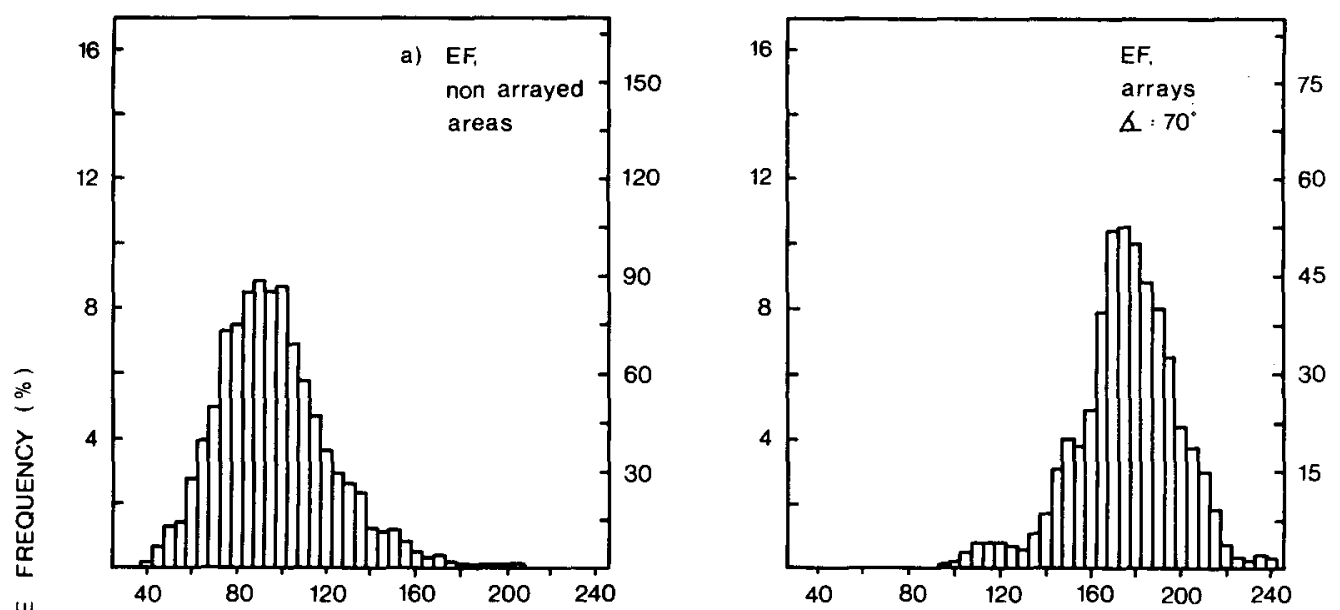

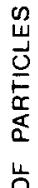
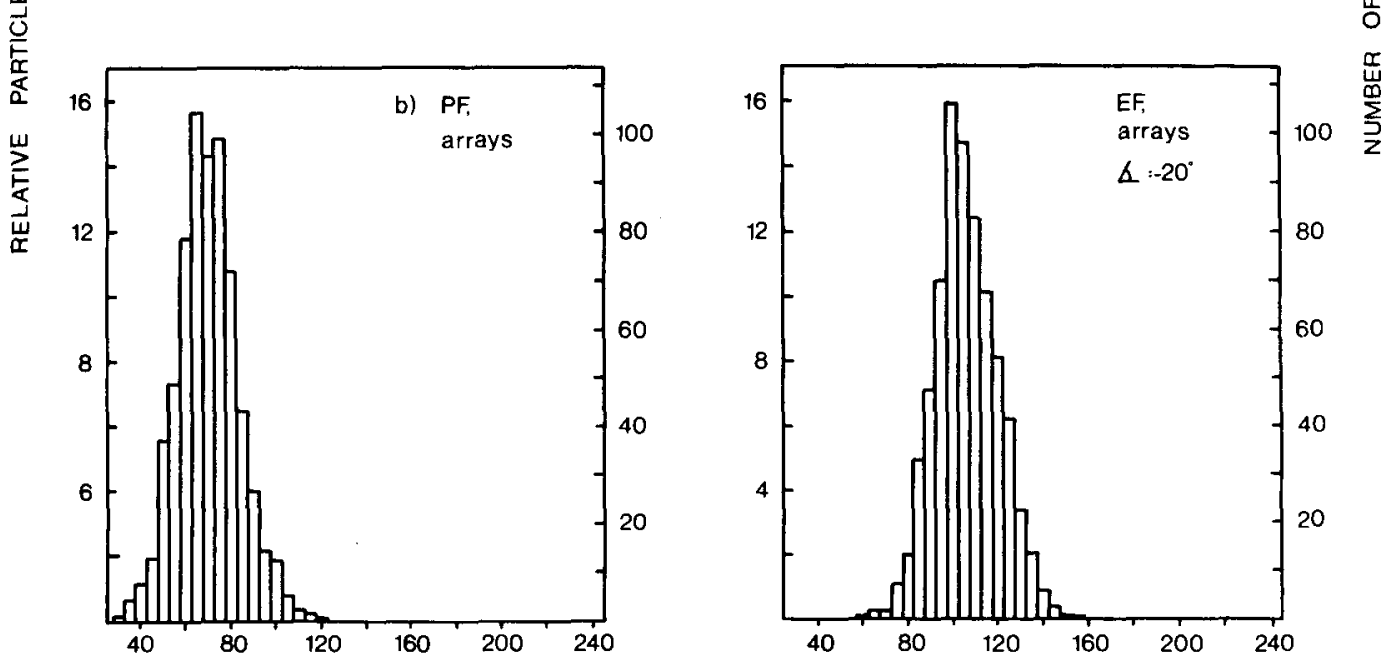

PARTICLE DIAMETER (A)

Figure 16. Histogram plots of the size distributions of the particles found in array-induced thylakoids from wildtype barley seedlings grown for 7 days in continuous white light. Value in parentheses is the angle between the direction of shadowing and the orientation of the array (see Table IV).

Two arrays in close proximity to one another on the EF face are shown in Figure 14. It can be seen that the particles are organised into a distorted hexagonal lattice, with axes inclined at $69^{\circ}$ and $42^{\circ}$ to one another. This was the most common type of array found on the EF face, although square lattices were found on the ES (Figures 19 and 20). The separation between rows was $175 \AA$ in two directions and $235.8 \pm 7.0 \AA$ ( \pm S.D. $)$ in the third. A maximum value of $247.5 \AA$ was measured for the latter distance, and might be a more reliable figure than the average because of distortion due to the uneven surface of the replica. These values are shown in the diagram in Figure 17.

One set of parallel rows can be distinguished from the other two, owing to the wider separation between rows $(247$ vs $175 \AA$ ). Using this set of rows as a reference, the orientation of arrays to one another, and to the direction of shadow- 


\section{J. SIMPSON: Freeze-fracture of barley chloroplast membranes}

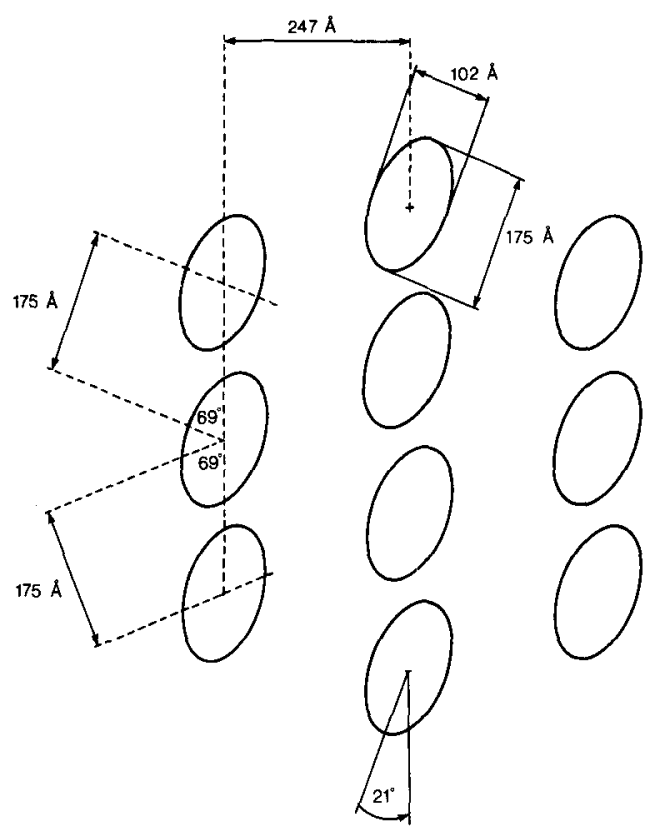

Figure 17. Diagrammatic representation of the size, arrangement and orientation of particles in EF arrays.

ing can be determined. In Figure 14, the reference rows are oriented at angles of $+38^{\circ}$ and $-20^{\circ}$ to the direction of shadowing. It is clear from this micrograph that the particle widths measured at right angles to the direction of shadowing, are uniform within an array, but differ between arrays depending on the orientation of the array to the direction of shadowing. The size distribution and average size of particles in arrays was measured as a function of the angle between the orientation of the array and the shadowing direction (Table IV, Figure 16). It was found that the minimum particle width occurred at an angle of approximately $-20^{\circ}$, and the maximum at about $70^{\circ}$. The values were $102.2 \AA$ and $175.5 \AA$ respectively, as also shown in the model of Figure 17.

Particle arrays were also present on the $\mathrm{PF}$ face of barley thylakoids (Figures 13 and 15). The number of particles per square micron was about $40 \%$ higher than that found for the de- stacked PF face, and may be even higher due to the errors involved in measuring such a dense population of small particles. The average particle was much smaller and more uniform in size in PF arrays than those found on the destacked PF face. They appeared to form double rows separated by deep groove (Figure 15) as found for spinach (36), with a spacing of $239.8 \pm$ 5.0Ả ( \pm S.D.).

Regular arrays with the same dimensions were also observed on the ES and PS of etched thylakoids. Incubation in $2 \mathrm{mM}-\mathrm{MgCl}_{2}$, $5 \mathrm{~mm}$-tris, $\mathrm{pH} 7.6$ induce a low frequency of arrays, but when they were present, they were located in ESs regions (Figures 19 and 20). Arrays were also found on the ES surface of thylakoids destacked in 5mM-tricine, $\mathrm{pH} 7.5$ (Figure 18 ), and a much higher frequency of arrays was observed when examining the ES of thylakoids incubated in 1 or $5 \mathrm{mM}$-HEPES, pH 7.5 (Figures 21 and 22). Particularly striking was the regular orientation and similar appearance of the particles comprising the arrays. The majority of arrays were distorted hexagonal lattices as shown in Figures 18 and 22, with the particles oriented at approximately $+20^{\circ}$ to the orientation of the array. This is consistent with the orientation of EF array particles $\left(-20^{\circ}\right)$, since an ES array is a mirror image of a EF array. (Care was always taken to place the replica platinum-side down in the microscope). Some ES arrays were square (19) rather than hexagonal (Figures 19, 20 , and 21 ), and depending on the direction of shadowing, the particles could be seen to be composed of tetramers (Figure 21).

Particle arrays were also seen, with difficulty, on the PS of thylakoids incubated in $5 \mathrm{mM}$-HEPES (Figures 23 and 24). These arrays were of low surface relief and were best visualised at low shadowing angles. The large particles on the PS, thought to be coupling factor molecules $(6,7,22)$ were largely excluded from arrayed areas.

It was possible to show in specimens that had been etched for $2 \mathrm{~min}$, that the rows of particles in arrays on the ES corresponded with the grooves in arrays on the PF face (Figures 25 and 26). Similarly the particles in PS arrays corresponded with arrays on the EF face (Figure 27). 

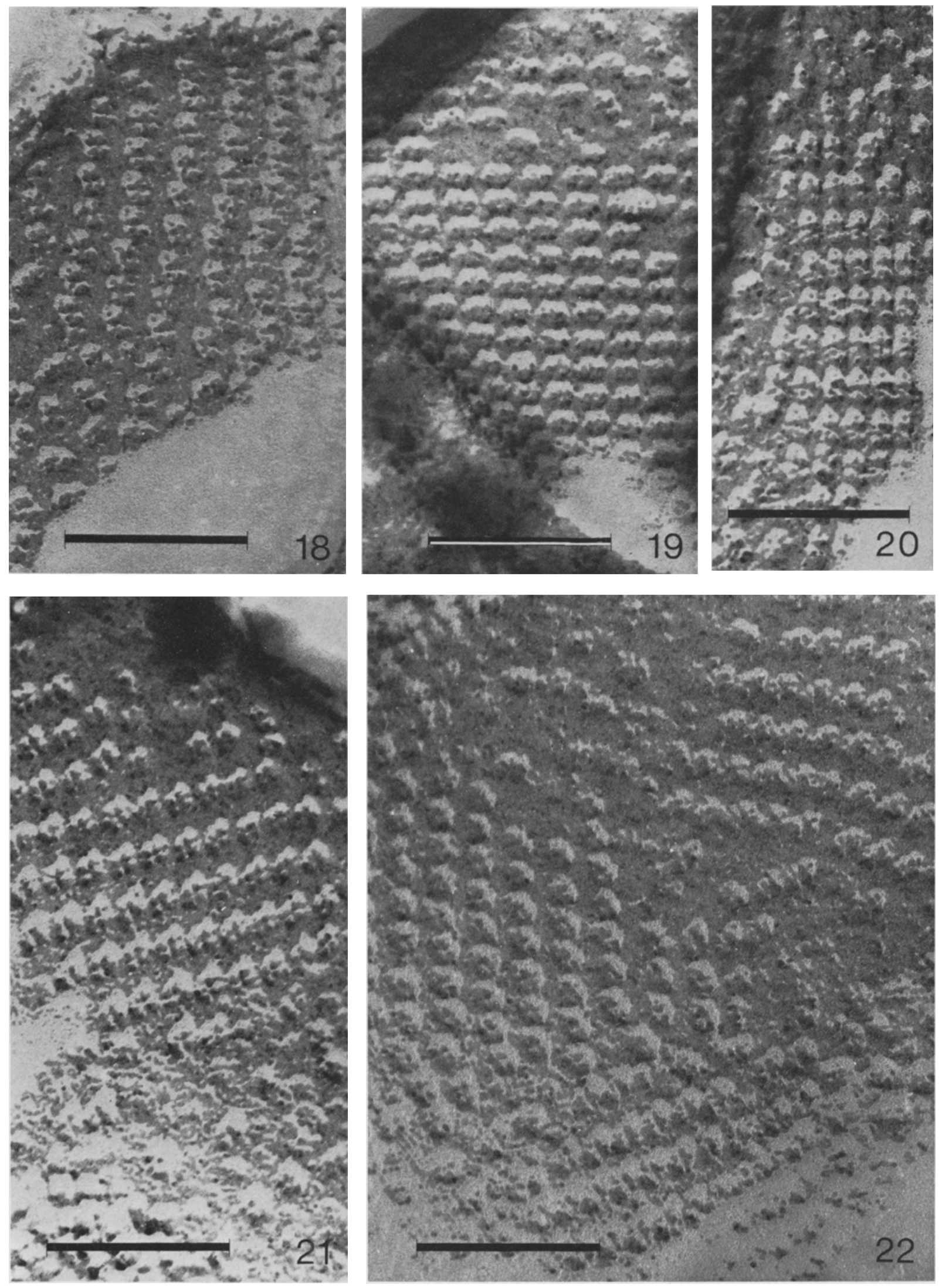
Figure 18. An array revealed on the inner thylakoid surface (ES) by freeze-etching, demonstrating the similarity between the component particles. Particles are oriented at an angle of about $+20^{\circ}$ to the main axis of the widely separated rows, consistent with the orientation of $-21^{\circ}$ estimated for EF particles. $\times 315,000(\mathrm{Bar}=0.1 \mu \mathrm{m})$.

Figures 19 and 20 . The effect of the direction of shadowing with respect to the orientation of the array, on the visualisation of particle fine structure, is shown in these two arrays on the ESs. $\times 315,000(\mathrm{Bar}=0.1 \mu \mathrm{m})$.

Figure 21. The tetrameric nature of the particles is clearly shown in this array on the ES of array-induced thylakoids. $\times 315,000(\mathrm{Bar}=0.1 \mu \mathrm{m})$.

Figure 22. Three separate arrays are almost touching on the ES of array-induced thylakoids, an indication of the large number of arrays seen in such preparations. $\times 315,000(\mathrm{Bar}=0.1 \mu \mathrm{m})$.
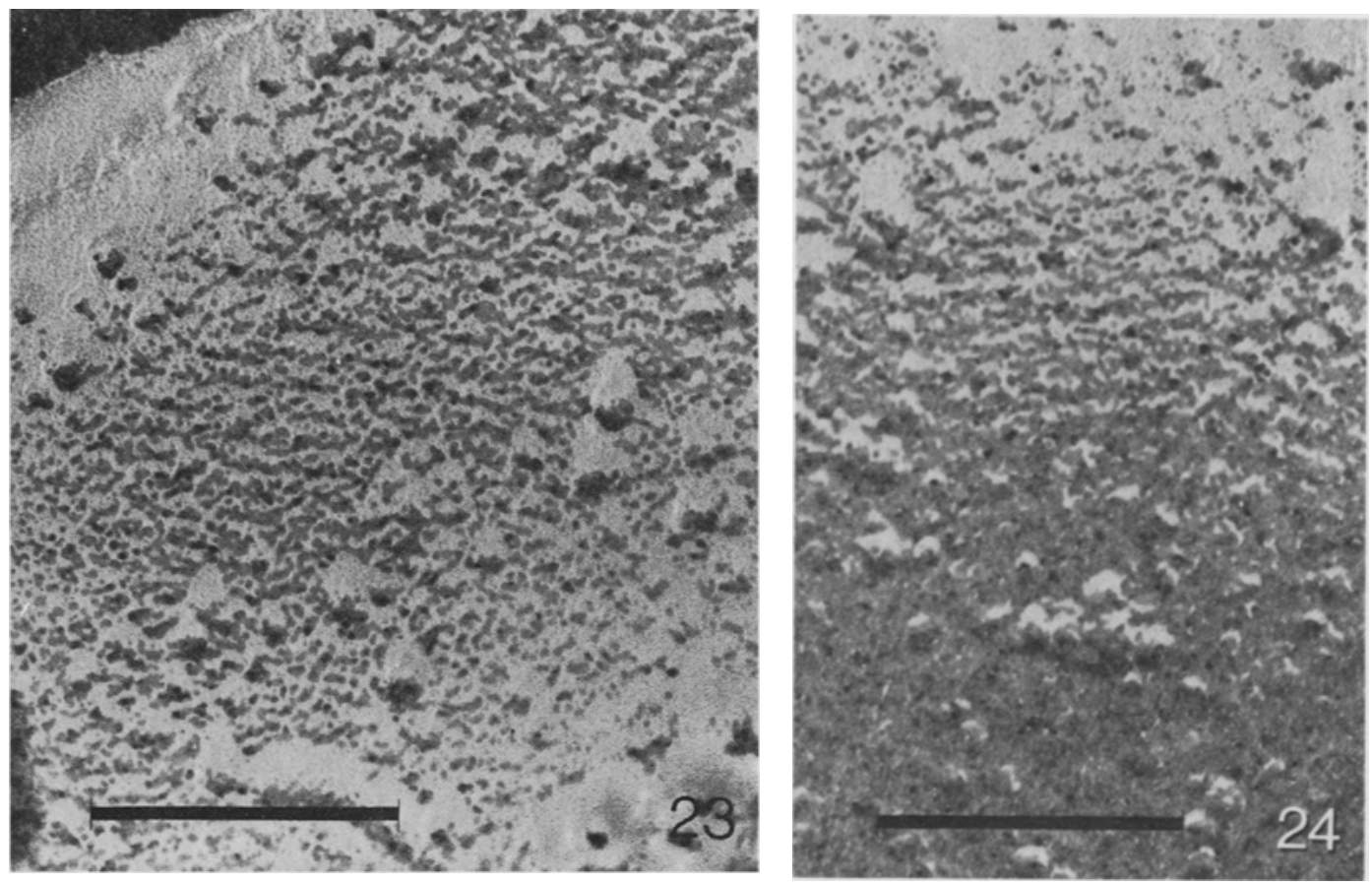

Figures 23 and 24. Regular arrays of particles are recognisable on the outer (PS) surface, but are difficult to see except at low shadowing angles because they protrude only a short distance above the membrane surface. The large particles (coupling factor 1 ) are excluded from these arrays. $\times 315,000(\mathrm{Bar}=0.1 \mu \mathrm{m})$. 

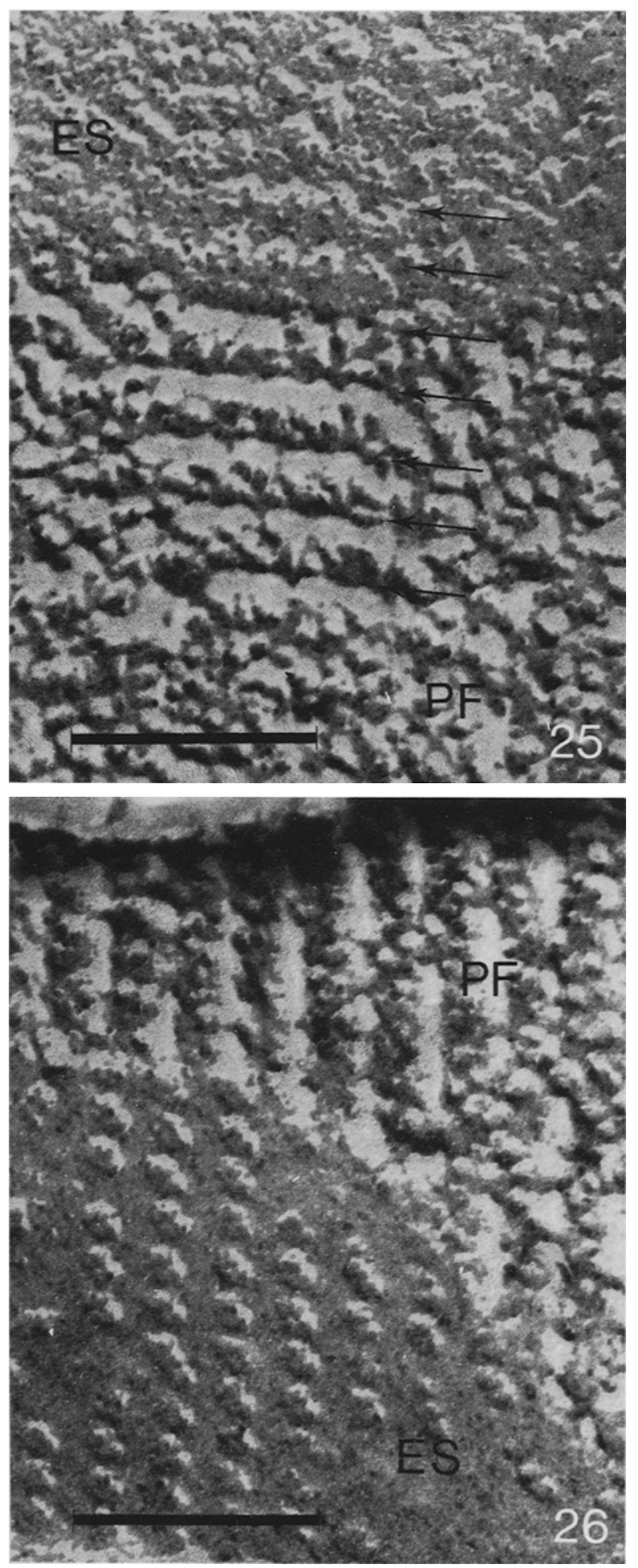

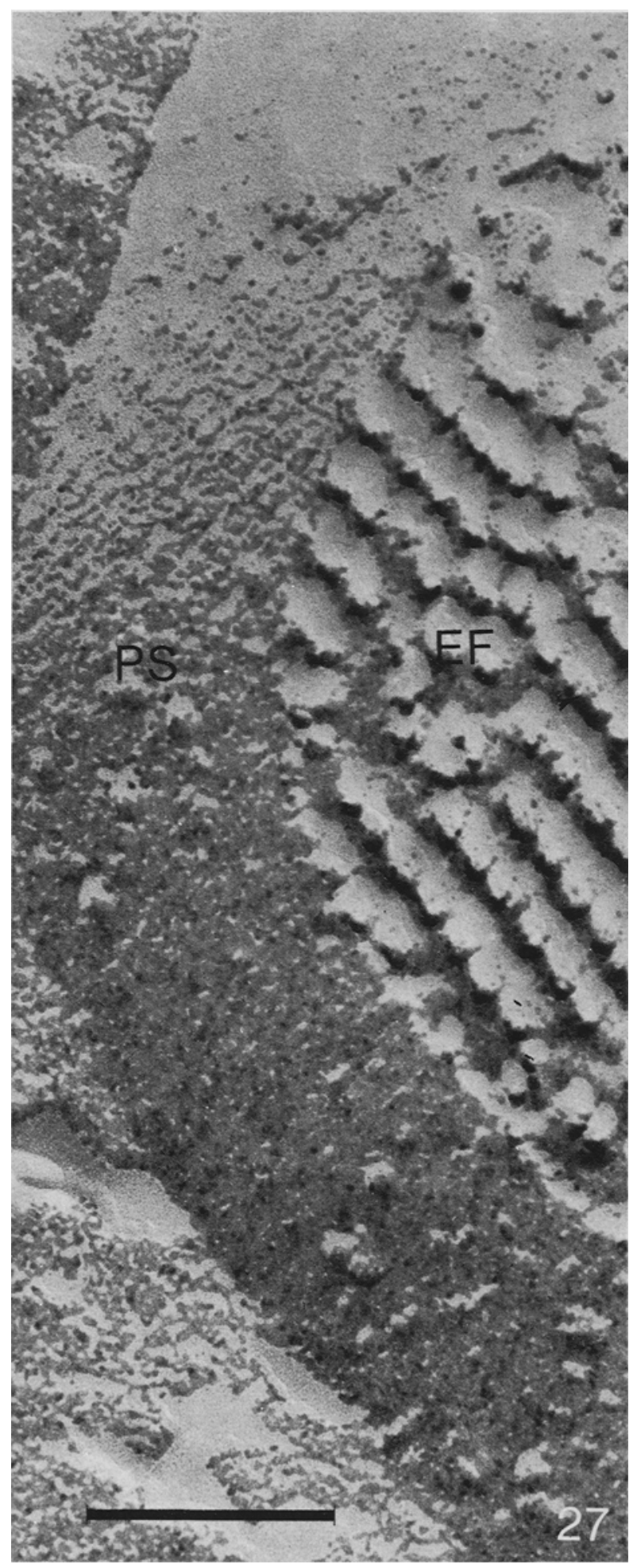


Figure 25. Freeze-etched thylakoid showing both the ES and PF face. The spacing between rows of ES particles (arrows) coincides with the rows of grooves in the PF arrays. $\times 315,000(\mathrm{Bar}=0.1 \mu \mathrm{m})$.

Figure 26. As in figure 25, showing more directly that rows of ES particles are continuations of the rows of grooves in the PF arrays. $\times 315,000(\mathrm{Bar}=0.1 \mu \mathrm{m})$.

Figure 27. Freeze-etched preparation showing the association between the EF arrays and the arrays on the PS. $\times 315,000(\mathrm{Bar}=0.1 \mu \mathrm{m})$.

\subsection{Chloroplast envelope membranes}

The chloroplast envelope consists of an inner and outer membrane, both of which freezefracture to yield two faces (EF and PF). The criteria used for identifying barley etioplast envelope membranes (32) were used for chloroplast envelopes, and the same terminology used. The freeze-fracture appearance of the EF and PF faces of the outer envelope membrane (OEF and OPF, respectively) is shown in Figures 28 and 29, and that of the EF and PF faces of the inner envelope membrane (IEF and IPF) in Figures 30 and 31 . Values measured for the freeze-fracture particle densities of chloroplast envelopes of barley and spinach are presented in Table V, and particle sizes and size distributions are given in Table VI and Figure 32.

\section{DISCUSSION}

The ultrastructure of freeze-fractured barley chloroplast thylakoids examined in this study is consistent with that reported by other workers $(9,10,12,13,19,27,30)$, and is not substantially different from that of thylakoids of other higher plants such as spinach $(22,23,26,36,37,38)$, maize $(20,31)$, lettuce (13), soybean (16), Portulaca (35), Alocasia (1), and pea $(2,3,4,5,28$, 29).

The greatest changes in membrane ultrastructure during greening of etiolated barley seedlings occur in the first $24 \mathrm{~h}$, which is when most of the changes in thylakoid polypeptide composition occur (14). There are substantial increases in both particle size and number per square micron, as can be seen when comparing thylakoids of plants grown for 6 days in the dark
(32) with those grown for 6 days in darkness followed by $24 \mathrm{~h}$ in light (Tables I and II). Similar changes have been noted during the greening of etiolated barley $(27,30)$ and Euglena (25).

The differences between chloroplast thylakoids from 7-day old barley seedlings exposed to light for 1 day or 7 days are relatively small. The major changes are an increase in the average size of EFu particles and in the number of EFu particles per square micron (Tables I and II). A similar, but smaller increase is found for EFs particles when comparing plants that have been grown in light for 1 or 7 days. It is known that the light intensity during growth can affect the density of freeze-fracture particles on the EFs face of Atriplex thylakoids $(9,10)$, although in this system other factors, such as the extent of grana formation and the chlorophyll $a / b$ ratio, are also involved.

Changes in the size of freeze-fracture particles have also been observed during the greening of intermittently illuminated ( 2 min light, 118 min dark) pea thylakoids under continuous white light $(3,4,5)$. Unlike the greening of etiolated tissue, which involves the synthesis and insertion of many polypeptides into the developing thylakoid (14), exposure of intermittently illuminated leaves to continuous light causes the insertion of a relatively small number of polypeptides (mainly the light-harvesting chlorophyll a/b protein complex) into a photosynthetically competent thylakoid (3). As such plants green, the size of freeze-fracture particles increased in discrete steps on both the PFu and EFu faces $(70$ or $80 \rightarrow 105 \AA)$ and EFs face $(80 \rightarrow$ $105 \rightarrow 132 \rightarrow 164 \AA)$, corresponding to the addition of discrete aggregates of light-harvesting complex to an EF "core" particle. This theory 

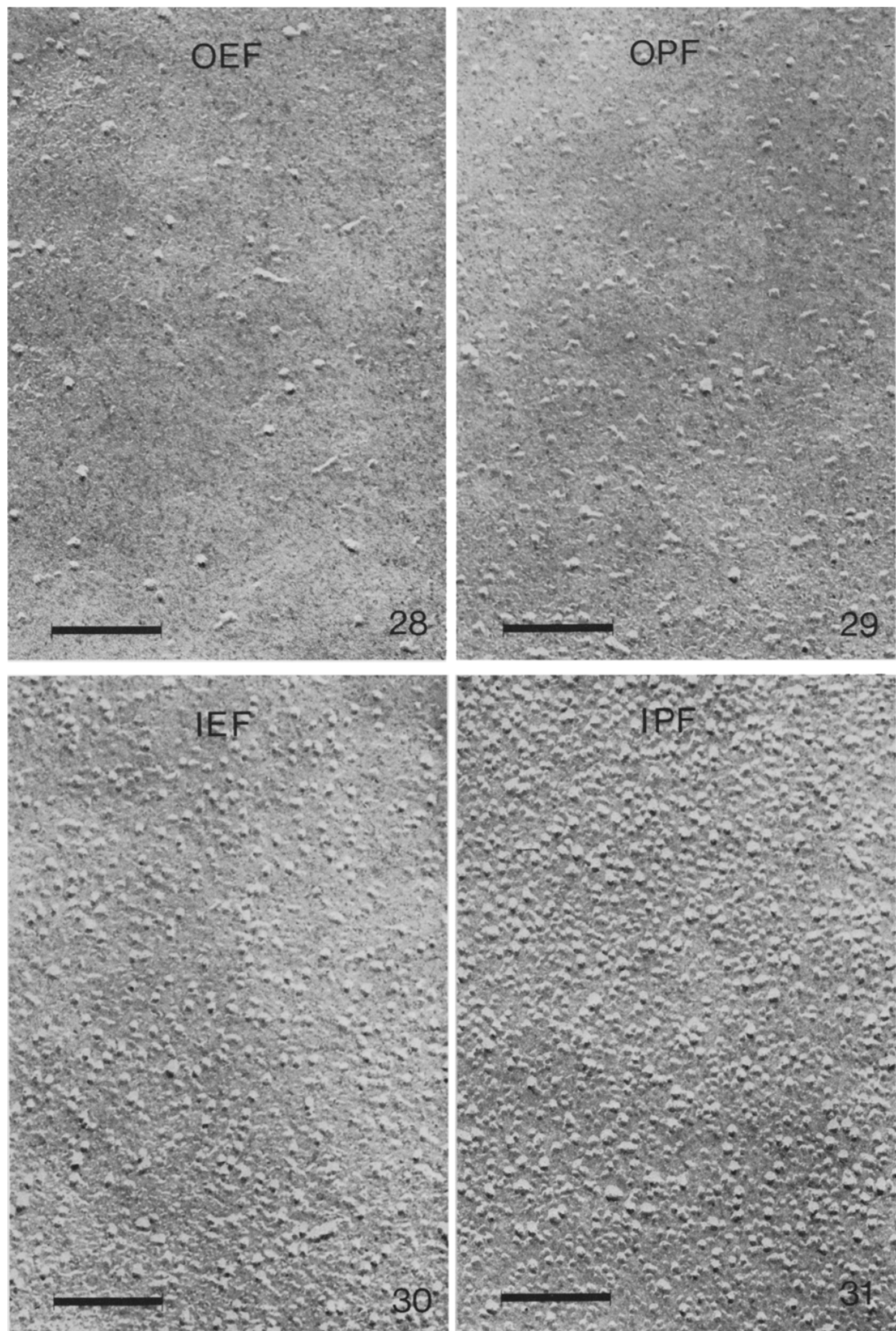

ropow

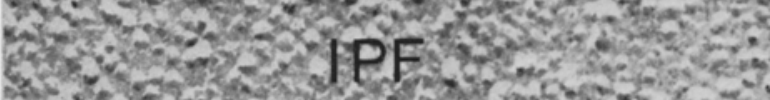

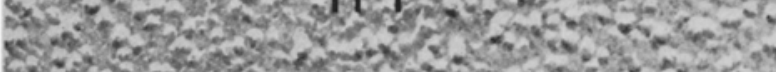

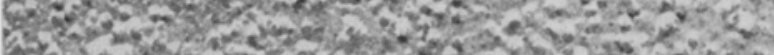

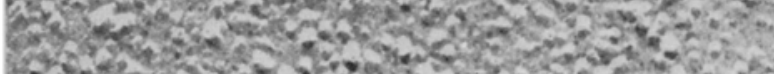

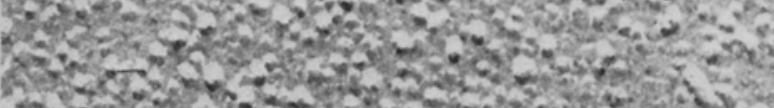

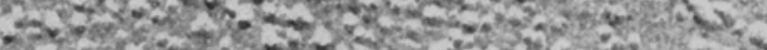

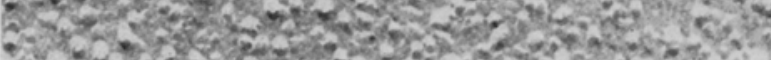

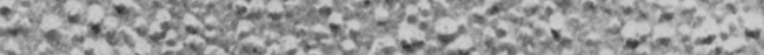

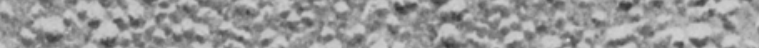

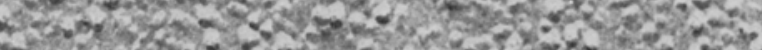

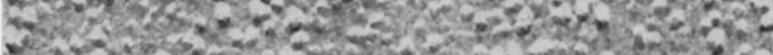

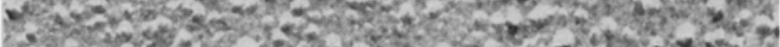

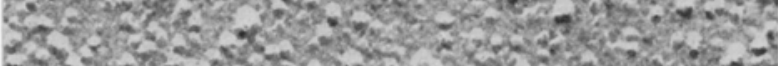

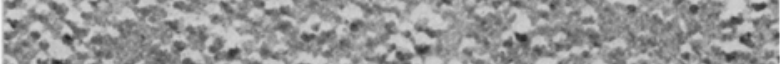

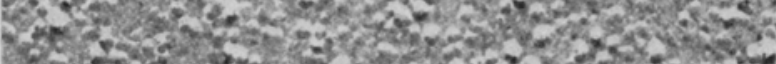

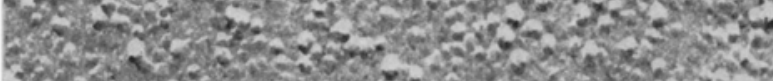

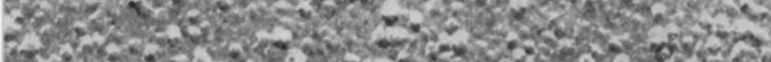

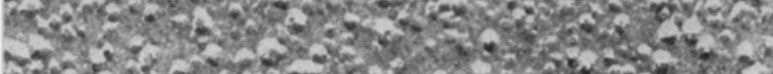

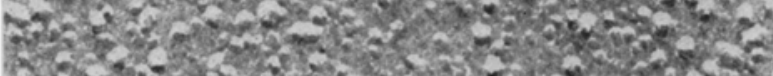

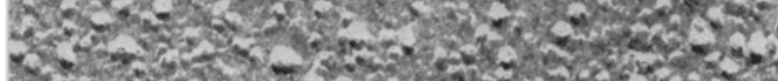

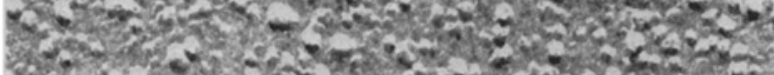

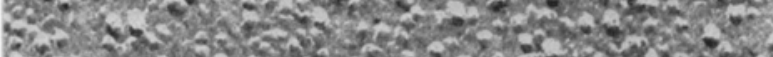

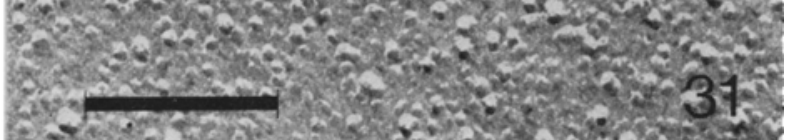

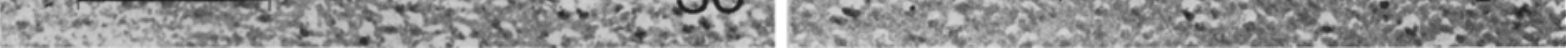




\section{J. Simpson: Freeze-fracture of barley chloroplast membranes}

Figures 28 and 29. The two complementary faces of the outer envelope membrane of barley chloroplasts are shown. The outer EF face (OEF) contains a low density of particles and the outer PF face (OPF) has about twice as many. $\times 195,000(\mathrm{Bar}=0.1 \mu \mathrm{m})$.

Figures 30 and 31 . The fracture faces of the inner envelope membrane (IEF and IPF) contain a much higher density of particles than the corresponding faces of the outer envelope membrane. $\times 195,000(\mathrm{Bar}=0.1 \mu \mathrm{m})$.

\section{Table V}

Freeze-fracture particle densities of plastid envelope membranes. S.E. $=$ standard error of the mean.

\begin{tabular}{llrc}
\hline Material & Face & No. $/ \mu \mathrm{m}^{2} \pm$ S.E. & Area measured $\left(\mu \mathrm{m}^{2}\right)$ \\
\hline Barley etioplast, & OEF & $766 \pm 14$ & 4.43 \\
6 days in dark & OPF & $1600 \pm 20$ & 2.60 \\
& IEF & $2390 \pm 43$ & 1.32 \\
Barley chloroplast, & IPF & $7492 \pm 73$ & 0.52 \\
6 days in dark, & OEF & $688 \pm 11$ & 6.61 \\
24h in light & OPF & $1295 \pm 15$ & 4.57 \\
& IEF & $2497 \pm 25$ & 2.28 \\
Barley chloroplast, & IPF & $7713 \pm 57$ & 0.56 \\
7 days in light & OEF & $428 \pm 13$ & 4.62 \\
& OPF & $881 \pm 15$ & 3.72 \\
& IEF & $2564 \pm 26$ & 2.20 \\
Spinach chloroplast, & IPF & $7423 \pm 82$ & 0.52 \\
mature leaves & OEF & $728 \pm 16$ & 2.86 \\
& OPF & $1873 \pm 14$ & 3.53 \\
& IEF & $2591 \pm 20$ & 2.83 \\
& IPF & $7407 \pm 73$ & 0.78 \\
\hline
\end{tabular}

is supported by the existence of two size populations of EFs particles in fully greened spinach (37) and pea (3) thylakoids. While the overall size changes that occur in EFs particles of barley thylakoids during greening (32, Table II) are similar to those of pea leaves, the particle sizes are distributed about a single broad mean (Figure 6; see also ref. 19). This does not mean that there is only one type of particle on the EF face of barley thylakoids, but that there is a continuum of particle sizes. Moreover, it would be difficult to resolve individual populations if the particles were asymmetric in shape.

The formation of regular arrays of particles, although requiring special conditions of preparation, permits additional information to be obtained about the nature of the freeze-fracture particles. This has been shown by MILLER et al.

\section{Table VI}

Freeze-fracture particle sizes of wild-type barley chloroplast envelope membranes S.D. $=$ standard deviation of population size distribution.

\begin{tabular}{lccc}
\hline Material & Face & Average size \pm S.D. $(\AA)$ & No. counted \\
\hline Seven days in light & OEF & $78.4 \pm 19.1$ & 700 \\
& OPF & $61.0 \pm 15.8$ & 500 \\
& IEF & $68.8 \pm 13.4$ & 1000 \\
& IPF & $63.1 \pm 13.7$ & 1000 \\
\hline
\end{tabular}


Table VII

Distribution of EF particles in 7-day old barley chloroplast thylakoids.

\begin{tabular}{llcc}
\hline Location & Area (\%) & \multicolumn{2}{c}{ Particles (\%) } \\
& & of total & of grana \\
\hline Grana & 44.4 & 64.5 & 100 \\
Arrays (average) & 21.9 & 44.2 & 68.5 \\
$\quad$ (maximum) & 29.0 & 58.6 & 90.5 \\
$\quad$ (minimum) & 17.9 & 36.1 & 56.0 \\
\hline
\end{tabular}
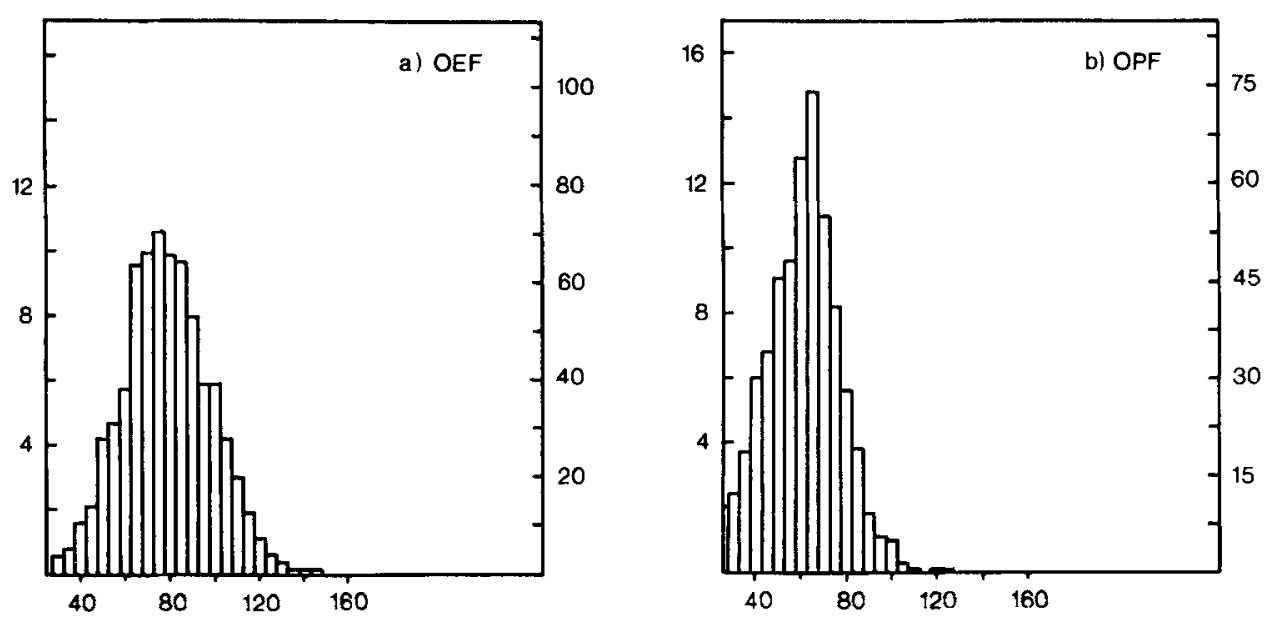

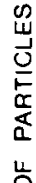
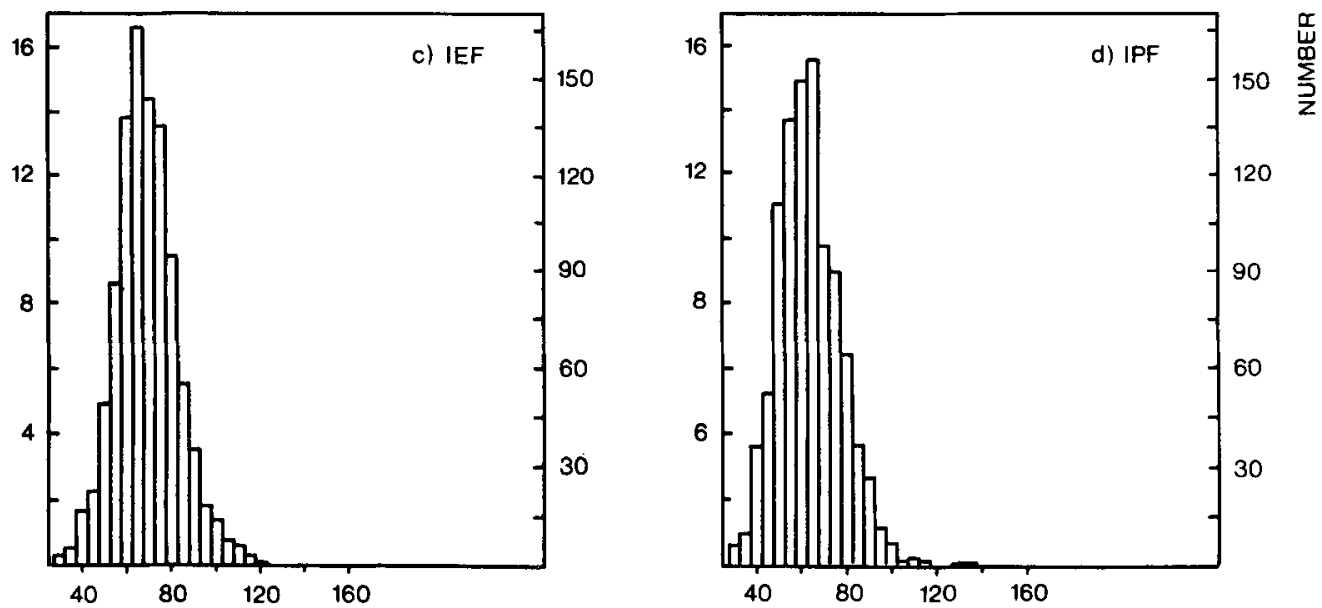

PARTICLE DIAMETER (A)

Figure 32. Histogram plots of the size distributions of the particles found on the freeze-fracture faces of the envelope membranes from wild-type barley chloroplasts. Average particle size and standard deviations are given in Table VI. 
(19) who demonstrated changes in the size of the EF particles in a chlorophyll b-less mutant of barley by measuring lattice spacings in particle arrays. It is therefore paticularly unfortunate that the procedure which induces arrays in barley so reproducibly, is not effective with other species. Such arrays are known to occur in spinach $(11,18,26)$ and pea $(28)$, but the conditions for their presence remain unknown. When arrays are found in stacked thylakoids, they are restricted to grana regions $(33,36)$ and are not found in stroma lamellae. It is likely that the ability to form arrays is a property unique to freeze-fracture particles originating from grana. Just as the average size of EFu particles is smaller than that of EFs particles (Table II), the average size of non-arrayed particles is smaller than those in arrays (Table IV). One can calculate the percentage of particles originating from grana and stroma lamellae (24) and similarly, the proportion of particles in arrays. These figures are given in Table VII and indicate that the number of particles in arrays is a high percentage of the number of particles originally in grana.

It seems reasonable to assume that EF particles in arrays are all similar in size and are uniformly aligned with one another, especially in view of the regular size and orientation of particles in ES arrays (Figures 18-22). One can obtain a measure of the asymmetry of arrayed EF particles by correlating particle width with the angle between the direction of shadowing (Table IV). It can thus be shown that the average particle in an EF array is $102 \dot{A}$ wide and 175A long (Figure 16). Since EFs particles (which are the source of EF array particles) are randomly oriented with respect to one another and to the direction of shadowing, it is to be expected that the apparent widths of a population of such asymmetrical particles are spread between the two extremes (102 and $175 \dot{A})$. It is possible, especially in view of the low average size of non-arrayed particles, that particles in EF arrays are larger than those in EFs regions, conceivably due to a redistribution of the lightharvesting complex as proposed by STAEHELIN (37).

Particles in arrays on the PF face are smaller on average than those on the destacked PF face
(Tables II and IV), again indicating that the particles in arrays are different from others on the same face. The ratio of the number of particles in PF and EF arrays is approximately 3:1, and may be $4: 1$, corresponding to the number of subunits in ES particles (18; see Figure 21). STAEHELIN (36) has shown that in stacked thylakoids, EFs particles in one disc make contact with PFs particles in the adjacent appressed disc. It is implicit in STAEHELIN's model that the arrayed PFs particles lie between the rows of EFs particles, and that the deep grooves between the double rows of PFs particles correspond to the rows of EFs particles. This model is confirmed by the measurements made on induced EF and PF arrays in destacked barley chloroplast thylokoids. The model in Figure 17 is readily able to accommodate four $70 \AA$ wide PF particles between two EF particles in adjacent rows. The possibility that the width of the PF particles determines the spacing of the widely separated rows in EF arrays should be considered.

MILLER (18) has suggested that the EF particle is a tetramer spanning the spinach thylakoid membrane, based on similarities between ES, EF and PS arrays. Although the relation between EF and PS particles has been directly shown $(18,26)$ the connection between EF and ES particles in less definite, especially in view of the existance of both EF and PF arrays in destacked thylakoids. It is clear, however, from Figures 25 and 26 that the rows of ES particles correspond with the rows of grooves in the PF arrays, not with the PF particles. This confirms MILLER's hypothesis that the particles in EF arrays span the thylakoid membrane, and furthermore indicates that the particles in PF arrays do not protrude sufficiently above either the ES or PS surfaces to be visualised by freeze-etching and shadowing. It has not been possible to directly correlate the other particle arrays on the PF face and ES (Figures 9-12).

Comparatively few studies have been carried out on the freeze-fracture ultrastructure of chloroplast envelopes, and there are considerable variations in particles densities reported $(8$, $21,34,35)$. There is general agreement that the inner envelope contains more freeze-fracture particles than the outer envelope. The values 
found for the envelopes of barley etioplasts (32) and chloroplasts (Table $V$ ) are much higher than those reported for spinach (34). When spinach chloroplast envelopes were examined using the same criteria as were applied for identifying barley etioplast envelopes (32), the values obtained for particle densities were similar to those for barley (Table V). The changes occurring during greening are limited to the outer envelope, where there is a progressive decrease in particle densities on both OEF and OPF faces as etioplasts transform into chloroplasts (Table V). The slight changes in particle sizes do not appear to be significant. The particle densities on the inner envelope membrane are remarkably constant both during greening and between chloroplasts of spinach and barley.

\section{ACKNOWLEDGEMENTS}

I am indebted to professor DITER vON WETT. sTEIN for suggesting this project and for helpful suggestions with the manuscript. Computer programs for measuring and statistically analysing particle widths were developed by cand. stat. Lisbeth SeJersen and JøRGEN PEeTz. I thank ANN-SOFI STEINHOLTZ for photography and NINA RASMUSSEN for drawing the figures. Financial support was provided by the Commission of European Communities contract 029-76-ES DK solar energy program.

\section{REFERENCES}

1. Anderson, J. M., D. J. Goodchild \& N. K. BOARDMAN: Composition of the photosystems and chloroplast structure in extreme shade plants. Biochim. Biophys. Acta 325, 573-585 (1973)

2. ARmond, P. A. \& C. J. ARnTZen: Localization and characterization of photosystem $1 \mathrm{I}$ in grana and stroma lamellae. Plant Physiol. 59, 398-404 (1977)

3. Armond, P. A., L. A. Staehelin \& C. J. ARntZEN: Spatial relationship of photosystem I, photosystem II, and the light-harvesting complex in chloroplast membranes. J. Cell Biol. 73, 400-418 (1977)

4. ARntzen, C. J.: Dynamic structural features of chloroplast lamellae. In: Current Topics in Bio- energetics (Eds.: D. R. Sanadi \& L. P. Vernon). Academic Press, N.Y. Vol. 7. (1978)

5. Arntzen, C. J., P. A. ARmond, J.-M. Briantais, J. J. BURKE \& W. P. NovitzKY: Dynamic interactions among structural components of the chloroplast membrane. Brookhaven Symp. Biol. 28, 316-337 (1976)

6. BERzBORN, R. J., F. KOPP \& K. MUHLethaler: Coupling factor $1\left(\mathrm{CF}_{1}\right)$, a mobile peripheral protein in the thylakoid surface of spinach chloroplasts. Proc. Third Internat. Congr. Photosyn., Rehovot 2, 809-820 (1974)

7. Berzborn, R. J., F. KopP \& K. MUhlethaler: Mobility of chloroplast coupling factor $1\left(C F_{1}\right)$ at the thylakoid surface as revealed by freezeetching after antibody labelling. Z. Naturforsch. 29C, 694-699 (1974)

8. Bisalputra, T. \& A. Bailey: The fine structure of the chloroplast envelope of a red alga, Bangia fusco-purpurea. Protoplasma 76, 443-454 (1973)

9. BoArdman, N. K., J. M. ANDERSON, O. BJORKMAN, D. J. GOOdChILD, L. H. GRImME \& S. W. THORNE: Chloroplast differentiation in sun and shade plants: relationship between chlorophyll content, grana formation, photochemical activity and fractionation of the photosystems. Port. Acta Biol. Ser. A 14, 213-236 (1974)

10. Boardman, N. K., O. Bjorkman, D. J. GoodCHILD \& S. W. THORNE: Photosynthetic adaptation of higher plants to light intensity: relationship between chloroplast structure, composition of the photosystems and photosynthetic rate. Proc. Third Internat. Congr. Photosyn., Rehovot 3, 1809-1827 (1974)

11. Garber, M. P. \& P. L. Steponkus: Alterations in chloroplast thylakoids during cold acclimation. Plant Physiol. 57, 681-686 (1976)

12. Henriques, F. \& R. B. Park: Further chemical and morphological characterization of chloroplast membranes from a chlorophyll b-less mutant of Hordeum vulgare. Plant Physiol. 55, 763-767 (1975)

13. Henriques, F. \& R. B. Park: Development of the photosynthetic unit in lettuce. Proc. Nat. Acad. Sci., USA 73, 4560-4564 (1976)

14. Høyer-HANSEN, G. \& D. J. SMmpSON: Changes in the polypeptide composition of internal membranes of barley plastids during greening. Carlsberg Res. Commun. 42, 379-389 (1977)

15. Kannangara, C. G., S. P. Gough, B. Hansen, J. N. RAsmussen \& D. J. SiMPSON: A homogenizer with replaceable razor blades for bulk isolation of active barley plastids. Carlsberg Res. Commun. 42, 431-439 (1977) 
16. KeCk, R. W., R. A. Dilley, C. F. Allen \& S. BIGGS: Chloroplast composition and structure differences in a soybean mutant. Plant Physiol. 46, 692-698 (1970)

17. Machold, O., D. J. Simpson \& G. Høyer-HaNSEN: Correlation between the freeze fracture appearance and polypeptide composition of thylakoid composition of thylakoid membranes in barley. Carlsberg Res. Commun. 42, 499-516 (1977)

18. Miller, K. R.: A particle spanning the photosynthetic membrane. J. Ultrastruct. Res. 54, 159-167 (1976)

19. Miller, K. R., G. J. Miller \& K. R. MCINTyre: The light-harvesting chlorophyll protein complex of photosystem II. J. Cell Biol. 71, 624-638 (1976)

20. Miller, K. R., G. J. Miller \& K. R. Mc Intyre: Organization of the photosynthetic membrane in maize mesophyll and bundle sheath chloroplasts. Biochim. Biophys. Acta 459, 145-156 (1977)

21. Miller, K. R. \& L. A. Stafhelin: Fine structure of the chloroplast membranes of Euglena gracilis as revealed by freeze-cleaving and deep-etching techniques. Protoplasma 77, 55-78 (1973)

22. Miller, K. R. \& L. A. Staehelin: Analysis of the thylakoid outer surface. Coupling factor is limited to unstacked membrane regions. J. Cell Biol. 68, 30-47 (1976)

23. MÜhlethaler, K.: Freeze-etch studies on chloroplast thylakoids. Proc. Second Internat. Congr. Photosyn., Stresa 2, 1423-1429 (1971)

24. Ojakian, G. K. \& P. SAtir: Particle movements in chloroplast membranes: quantitative measurements of membrane fluidity by the freeze-fracture technique. Proc. Nat. Acad. Sci., USA 71, 2052-2056 (1974)

25. Ophir, I. \& Y. Ben-Shaul: Structural organization of developing chloroplasts in Euglena. Protoplasma 80, 109-127(1974)

26. PARK, R. B. \& A. O. PFEIfHOFER: Ultrastructural observations on deep-etched thylakoids. J. Cell Sci. 5, 299-311 (1969)

27. Phung Nhu Hung, S., A. Lacourly \& C. Sarda: Etude de l'évolution en chloroplastes des plastes étiolés d'orge I. Structure éxaminée par cryodécapage. Z. Pflanzenphysiol. 62, 1-16 (1970)

28. Popov, V. I., B. L. AllakhVerdov \& S. V. TAGEEVA: Investigation of the supramolecular or- ganization of photosynthetic membranes by the freeze-fracture method. Dokl. Biophys. 229-231, 168-171 (1976)

29. Popov, V. I., S. V. Tageeva, B. S. Kaurov, A. G. Gavrilov, A. B. Rubin \& L. B. Rubin: Effect of ruby laser illumination on the ultrastructure of pea chloroplast membranes. Photosynthetica 11 , 76-80 (1977)

30. Remy, R., S. Phung Nhu hung \& A. Moyse: La différenciation fonctionnelle et structurale au cours du verdissement des étioplastes. Quelques apercus sur la mise en place des deux systèmes photochimiques. Physiol. Vég. 10, 269-290 (1972)

31. Sil.aev, A. M., D. A. Moshkov, M. S. Gamayunova \& L. K. Ostrovskaya: Structure of granal and intergranal thylakoids in corn thylakoids according to freeze-fracture data. Dokl. Biophys. 226, 3-5 (1975)

32. SIMPSON, D. J.: Freeze-fracture studies on barley plastid membranes I. Wild-type etioplast. Carlsberg Res. Commun. 43, 145-170 (1978)

33. Simpson, D. J., G. Høyer-Hansen, N.-H. Chua \& D. voN WETTSTEIN: The use of gene mutants in barley to correlate thylakoid polypeptide composition with the structure of the photosynthetic membrane. Proc. Fourth Internat. Congr. Photosyn., Reading pp. 537-548 (1977)

34. Sprey, B. \& W. M. Laetsch: Chloroplast envelopes of Spinacia oleracea L. III. Freeze-fracturing of chloroplast envelopes. Z. Pflanzenphysiol. 78, 360-371 (1976)

35. SPREY, B. \& W. M. LAETSCH: Structural studies of peripheral reticulum in $\mathrm{C}_{4}$ plant chloroplasts of Portulaca oleracea L. Z. Pflanzenphysiol. 87, 37-53 (1978)

36. Stafhelin, L. A.: Chloroplast membrane structure. Intramembranous particles of different sizes make contact in stacked membrane regions. Biochim. Biophys. Acta 408, 1-11 (1975)

37. Staehelin, L. A.: Reversible particle movements associated with unstacking and restacking of chloroplast membranes in vitro. J. Cell Biol. 71, 136-158 (1976)

38. Staehelin, L. A., P. A. Armond \& K. R. Miller: Chloroplast membrane organization at the supramolecular level and its functional implications. Brookhaven Symp. Biol. 28, 278-315(1976) 